\title{
1 Mitotic spindle formation in the absence of Polo kinase
}

2

\author{
Juyoung $\operatorname{Kim}^{1}$ and Gohta Goshima ${ }^{1,2 *}$
}

${ }^{1}$ Division of Biological Science, Graduate School of Science, Nagoya University, Furocho, Chikusa-ku, Nagoya 464-8602, Japan

${ }^{2}$ Sugashima Marine Biological Laboratory, Graduate School of Science, Nagoya University, 429-63 Sugashima, Toba 517-0004, Japan

${ }^{*}$ Correspondence should be addressed to goshima@bio.nagoya-u.ac.jp

Phone: +81 599-34-2216

\begin{abstract}
Mitosis is a fundamental process in every eukaryote, in which chromosomes are segregated into two daughter cells by the action of the microtubule (MT)-based spindle. Despite this common principle, genes essential for mitosis are variable among organisms. This indicates that the loss of essential genes or bypass-of-essentiality (BOE) occurred multiple times during evolution. While many BOE relationships have been recently revealed experimentally, the BOE of mitosis regulators (BOE-M) has been scarcely reported and how this occurs remains largely unknown. Here, by mutagenesis and subsequent evolutionary repair experiments, we isolated viable fission yeast strains that lacked the entire coding region of Polo-like kinase (Plk), a versatile essential mitotic kinase. The BOE of Plk was enabled by specific mutations in the downstream machinery, including the MT-nucleating $\gamma$-tubulin complex, and more surprisingly, through downregulation of glucose uptake, which is not readily connected to mitosis. The latter bypass was dependent on casein kinase I (CK1), which has not been considered as a major mitotic regulator. Our genetic and phenotypic data suggest that CK1 constitutes an alternative mechanism of MT nucleation, which is normally dominated by Plk. A similar relationship was observed in a human colon cancer cell line. Thus, our study shows that BOE-M can be achieved by simple genetic or environmental changes, consistent with the occurrence of BOE-M during evolution. Furthermore, the identification of BOE-M constitutes a powerful means to uncover a hitherto under-studied mechanism driving mitosis and also hints at the limitations and solutions for selecting chemotherapeutic compounds targeting mitosis.
\end{abstract}

\section{Introduction}

Different organisms have different sets of essential genes for their viability and propagation $(1,2)$. This indicates that most 'essential' genes are context-dependent and can become dispensable during evolution. Plausibly, a loss of essentiality is compensated for by manifestation of an alternative, currently 'masked', or far less active mechanism to ensure a similar cellular activity. Many experimental efforts have been made to recapitulate the molecular diversity found in nature (3). Large-scale systematic surveys have been recently conducted in budding and fission yeasts, in which a number of bypassof-essentiality (BOE) events have been identified (4-7). In these studies, suppressors were screened for haploid strains in which an essential gene was experimentally disrupted. For 9-27\% of the essential gene disruptants, a mutation or overexpression of other gene(s), or chromosomal gain makes the strain viable, indicating that essentiality depends on 
genetic background and that BOE could indeed occur at a certain frequency. However, in most cases, the underlying mechanism remains unexplored. It is also unclear why BOE is rarely observed in certain processes such as mitotic cell division.

Mitotic cell division is controlled by many essential genes in a given cell type (8-10). Evolutionary evidence of BOE is clearly visible for this fundamentally critical biological process. One striking example is the centrosome, which is assembled by the action of many essential proteins in animal, fungal, and algal species, and plays a vital role in cell division and cellular motility (11). However, the centrosome and most of its components have been lost in land plants, and yet plant cells undergo spindle assembly and chromosome segregation at high fidelity (12). Kinetochore components, such as the CCAN complex, spindle microtubule (MT)-associated proteins, such as TPX2, augmin, and mitotic motors, and cell cycle regulators, such as anaphase-promoting complex/cyclosome are among other examples; they are not universally conserved or essential factors (12-15). Despite the evidence of BOE for almost all the genes involved in mitosis, only a limited number of cases can be found in experimental BOE screening. For example, two random BOE screenings in fission yeast encompassing 23 mitotic genes have identified only a single protein, Cnp20/CENP-T, despite the fact that $>20 \%$ BOE has been observed for mitosis-unrelated genes $(6,7)$. The BOE of cnp20 is conceivable, as CENP-T functions in parallel with CENP-C for kinetochore assembly $(16,17)$. Another known BOE of mitosis regulators (BOE-M) in fission yeast is MT plus-enddirected kinesin-5/Cut7, which is required for bipolar spindle formation through force generation on spindle MTs. The viability of $c u t 7 \Delta$ was restored when the opposing minusend-directed kinesin-14/Pkl1 was simultaneously deleted. Thus, the balance of forces applied to spindle MTs is critical (18-20). However, many other essential mitotic genes have no apparent functionally redundant or counteracting factors, and whether these relationships are general mechanisms of BOE-M is unclear. Essential mitotic genes are potential targets of cancer chemotherapy (21); it is also important to understand the BOE that underlies drug resistance.

In this study, we found that the essentiality of the sole Polo-like kinase (Plk) in fission yeast (Plo1) can be bypassed. Plo1, similar to human Plk1, is assumed to be essential for spindle MT formation and spindle bipolarisation. However, these essential processes were restored in the absence of Plo1 by multiple independent mechanisms that increase MT nucleation and stabilisation, one of which involved a remarkably simple change in glucose concentration in the culture medium and depended on casein kinase I (CK1). Thus, our study uncovered an unexpected alternative mechanism of spindle MT formation and further implies that more BOE-M can be recapitulated in the experimental system.

\section{Results}

\section{Viable yeast cells without Polo-like kinases in several genetic backgrounds}

Our previous BOE screening randomly selected 93 genes on chromosome II, which encompassed 12 mitotic genes (7). BOE-M could not be detected in any of these genes. To further screen for BOE-M, we selected eight other mitotic genes (ark1, birl, fta2, fta3, mis6, mis 14, picl, and plol) and applied the same screening method. Seven days after plating and UV mutagenesis of spores of each disruptant, we found a growing haploid colony for plo1 $\Delta$, the sole Polo-like kinase (Plk) in Schizosaccharomyces pombe (Fig. 1A, 94 first step). Plks play versatile roles in animal cell division, including centriole duplication 
95 (by Plk4), centrosome maturation, spindle assembly checkpoint satisfaction, and

96 cytokinesis (by Plk1). It is also a possible target for cancer chemotherapy (21-23). The

97 responsible suppressor mutation was identified through whole genome sequencing

98 (WGS) followed by genetic crossing, which turned out to be ght5 (Fig. 1B, left, fourth

99 line). In $S$. pombe, eight hexose transporters have been identified, which show different

100 affinities to glucose; Ght5 is a major hexose transporter with the strongest affinity to

101 glucose and plays a critical role in glucose uptake (24). This prompted us to test and found

102 that the plo1s strain grows, albeit slower than the wild-type, when the glucose

103 concentration of the medium was lower than $0.3 \%$ (Fig. 1B, left, third line, Fig. S1A).

104 Thus, plo1s became viable under low-glucose conditions. To obtain a full scope of

105 suppressor mutations, we repeated the UV mutagenesis of plo1s spores on a larger scale,

106 obtained multiple colonies, and determined the responsible mutations. Simultaneously,

107 an 'experimental evolution' (EVO) (also called 'evolutionary repair' (3)) experiment was

108 conducted for the plo1s strain in low-glucose medium $(0.08 \%)$, in which serial dilution

109 and saturation enriches the cells that have acquired beneficial mutations for proliferation

110 (Fig. 1A, ' $1{ }^{\text {st }}$ EVO'). The faster growing strains obtained through this step were subjected

111 to further evolutionary repair experiments in high-glucose medium (' ${ }^{\text {nd }}$ EVO') and at a

112 different temperature (' $3{ }^{\text {rd }} E V O$ ').

113 We determined the whole genome sequences of several viable plo1s strains and

114 confirmed the suppressor mutations by independently generating a double mutant with

115 plo1 $\Delta$. In total, 16 genes were found to assist in the growth of the otherwise inviable

116 plo1 $\Delta$ strain (Fig. 1B, D; S1B, C). An example of the evolutionary repair process is shown

117 in Fig. S1D. This strain acquired mutations in alp6 and aps 1 during the $1^{\text {st }}$ EVO but still

118 possessed the benefit of plo $^{+}$gene for strain fitness (Fig. S1D, left). However, additional

119 mutations in mipl and ahkl during the $2^{\text {nd }}$ EVO bypassed the requirement of Plo1, since

120 adding back the plo1+ gene to the original locus did not further promote colony growth

121 (Fig. S1D, right). Most of the responsible genes were categorised into three classes: Spt-

122 Ada-Gen5 acetyltransferase (SAGA) complex, glucose/PKA pathway, and MT

123 regulators (Fig. 1D). The SAGA complex is a general regulator of transcription,

124 possessing histone acetyltransferase activity, and affects the expression of many genes

125 (25). We did not analyse this in the present study. The cAMP-PKA pathway is linked to

126 glucose homeostasis in fission yeast. Glucose is detected by a receptor (Git3), and the G-

127 protein complex (Gpa2, Git5, and Git11) is activated, which then activates adenylate

128 cyclase (Cyr1) to produce cAMP (26). Eventually, cAMP releases the inhibitor Cgs 1 from

129 Pka1, converting Pka1 to its active form (27). Furthermore, yeast cells regulate glucose

130 uptake by changing the localisation and transcriptional level of hexose transporters,

131 including Ght5, depending on environmental conditions $(24,28,29)$. There is a link

132 between glucose/PKA and MT stabiliser CLASP (cytoplasmic linker-associated protein)

133 during interphase (30). In our case, mutations in MT regulators (alp4, alp6, and asp1) and

134 glucose/PKA-pathway genes additively supported the growth of plo1s (Fig. 1B).

135

136

137

138

139

\section{Monopolar spindles predominate during mitosis in the absence of Polo}

The major MT nucleator at the centrosome is the $\gamma$-tubulin ring complex $(\gamma$-TuRC), which consists of $\gamma$-tubulin and GCP subunits, including GCP2 (Alp4/Spc97) and GCP3 (Alp6/Spc98) (31). In animal cells, Plk1 is a critical regulator of mitosis, which is, in the

140 early stage, required for $\gamma$-TuRC recruitment to the centrosome and thus centrosome 
maturation; inhibition of Plk1 leads to monopolar spindle formation $(22,32)$. In fission yeast, cytokinesis/septation defects are most profoundly observed in plol mutants, whereas monopolar spindle formation has also been described (33-37). However, actual spindle dynamics have not been analysed for plols in live imaging. To analyse spindle dynamics in the absence of Plo1, live imaging of mCherry-tubulin and a spindle pole body (SPB) marker, either Sad1 $1^{\mathrm{SUN}}$-GFP or Alp6 ${ }^{\mathrm{GCP} 3}$-GFP, was performed after plo1 $\Delta$ spore germination with spinning-disc confocal microscopy (Fig. 2A-E). The control cell assembled bipolar spindles immediately after the disappearance of interphase MT networks (Fig. 2A and D: time 0 corresponds to the onset of mitosis), and cell division was completed in $\sim 30 \mathrm{~min}$. In contrast, 53 out of 56 plo1 $\Delta$ cells after spore germination were arrested with a monopolar spindle for $>1 \mathrm{~h}$ (Fig. 2B, C, E, wherein stronger laser exposure was applied in Fig. $2 \mathrm{C}$ to visualise the faint $\mathrm{MT}$ signals).

We compared the phenotype with other known mutants that show monopolar spindle formation, including Cut12, which drives SPB insertion into the nuclear envelope (NE) $(38,39)$, Cut $7^{\text {kinesin-5 }}$, which is required for anti-parallel MT crosslinking and sliding $(40)$, and Cdc31 $1^{\text {centrin }}$, which is required for SPB duplication (41). In the cut12-1 temperaturesensitive (ts) mutant, the lack of insertion of one of the duplicated SPBs causes partial breakage of the NE and detachment of an SPB from the NE $(38,42)$. In another study, Plo1 was shown to regulate the formation of the Sad1 ${ }^{\text {SUN }}$ ring structure, which might be required for SPB insertion (43). We assessed the integrity of the NE in plo1 $\Delta$. First, we tagged GFP to Pcp $1^{\text {PCNT }}$, a core SPB component $(35,44)$, in the plo1 $\Delta$ background. In contrast to the cut12-1 mutant, we always detected punctate Pcp ${ }^{\text {PCNT }}$-GFP signals $(\mathrm{n}=$ 20 ) at the pole of the monopolar spindle, suggesting that SPBs in the NE generate spindle MTs in the absence of Plo1 (Fig. S2A, B). Next, we conducted an NLS-GFP efflux assay, in which partial NE breakage because of SPB insertion error leads to nuclear GFP signal efflux into the cytoplasm (38). We first confirmed the efflux in the cut12-1 ts mutant; GFP started to leak out from the nucleus $18 \pm 10 \mathrm{~min}$ after interphase spindle disassembly at non-permissive temperatures in 20 out of 20 cells that assembled monopolar spindles (Fig. S2D, 20, 30, and $70 \mathrm{~min}$; (38)). In contrast, plols cells maintained GFP signals inside the nucleus during the early stage of mitosis, similar to the control strains (Fig. $\mathrm{S} 2 \mathrm{C}$ ). These data suggest that SPBs are properly inserted into the NE at the onset of spindle formation in the absence of Plo1. Notably, GFP efflux during mitotic arrest occurred in 16 out of 20 plol $\Delta$ cells ( $69 \pm 18 \mathrm{~min}$ after spindle assembly), suggesting that $\mathrm{NE}$ was partially dissolved during prolonged arrest (Fig. S2C, 100 and $200 \mathrm{~min}$ ).

Next, we isolated $c u t 7 \Delta$ and $c d c 31 \Delta$ spores with Alp6 ${ }^{\mathrm{GCP} 3}$-GFP (SPB) and mCherrytubulin markers and germinated them in normal culture medium. As expected, monopolar spindles were prevalent in each sample, with only a single dot of Alp6 ${ }^{\mathrm{GCP}}$-GFP detectable at the end of spindle MTs (Fig. 2F, G). However, Alp6 ${ }^{\mathrm{GCP} 3}$-GFP signal intensity was significantly lower in the plo1 $\Delta$ spindles than in $c u t 7 \Delta$ or $c d c 31 \Delta$ (Fig. $2 \mathrm{H}$ ). Consistent with this phenotype, spindle MTs were dimmer in plol $\Delta$ (compare Fig. 2E and 2F/G) and plo1 $\Delta$ was sensitive to thiabendazole (TBZ), an MT-destabilising drug (Fig. S3A). Finally, we checked whether Cut $7^{\text {kinesin-5 }}$ localisation was defective in plo1 $\Delta$, which would cause

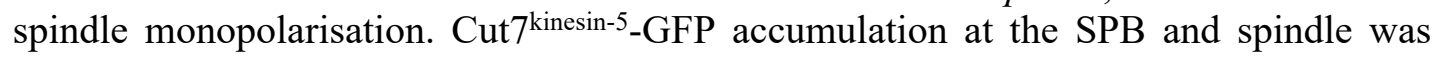
delayed in the absence of plol (Fig. S3B, $0 \mathrm{~min}$ ). However, the signals gradually recovered and reached a level comparable to the early prometaphase of control cells, at which spindle bipolarity was not recovered (Fig. S3C). Thus, it is unlikely that failure in 
Cut7 kinesin-5 recruitment is the major cause of spindle monopolisation in plol $\Delta$. Rather, our data favour the model whereby decreased MT nucleation at SPB leads to spindle monopolisation in plo1 $\Delta$. Consistent with this notion, monopolar spindles have been observed in mutants of the $\gamma$-TuRC component (Alp4 ${ }^{\mathrm{GCP} 2}$ ) (45).

\section{Modulation of MT nucleation and stability bypassed Polo essentiality}

Two BOE strains had point mutations in alp $4^{G C P 2}$ and alp $6^{G C P 3}$. Double alp4-D440E plo1 $\Delta$ and alp6-V664F plo1 1 strains recovered colony-formation ability in normal (highglucose) medium (Fig. 1B). Thus, the essentiality of Plo1 was bypassed by a single specific mutation in the MT nucleating machinery. We also performed a spot test for single alp6-V664F and alp4-D440E mutants (Fig. 1C). alp6-V664F grew more slowly than the wild-type, whereas no difference in colony growth was observed for alp4-D440E.

We investigated whether the mutation in alp 4 could restore $\gamma$-TuRC recruitment to the SPB in the absence of plo1. To address this, we isolated a double alp4-D440E plo1 $\Delta$ mutant with Alp6 ${ }^{\mathrm{GCP} 3}$-GFP and mCherry-tubulin markers (Fig. 3A). Quantification indicated that both GFP and mCherry signals were partially but significantly restored by the alp4-D440E mutation (Fig. 3B, C). In $50 \%$ of the cells $(\mathrm{n}=46)$, spindle bipolarity was recovered after a delay and cytokinesis was completed (Fig. 3A, left), whereas monopolar states were persistent for $>60 \mathrm{~min}$ in $30 \%$ of the cells (Fig. 3B, right), explaining the partial rescue of the viability by this specific mutant of alp4. Consistent with frequent spindle bipolarisation, GFP efflux in the viable alp4-D440E plo1 $\Delta$ and ght $5 \Delta$ plol $\Delta$ strains was less frequently observed than in single plo $1 \Delta(19 \%$ and $21 \%, \mathrm{n}$ $=26$ and 48) (Fig. S2E, F).

Asp1 ${ }^{\text {PPIP5K/Vip1 } 1}$ is another MT-related factor and its mutation assisted in the growth

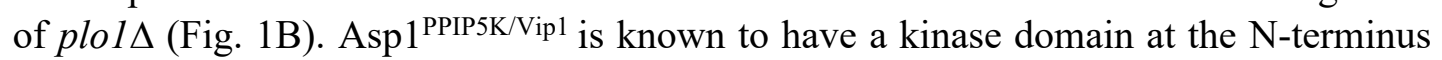
and a phosphatase domain at the C-terminus, and the latter is required for MT destabilisation (46). Interestingly, two mutations acquired during experimental evolution were located at the C-terminus (Fig. 1D). The mutation did not affect colony growth in the presence of Plo1 (Fig. 1C). However, time-lapse imaging showed that the asp1$D 507 G$ plo1s strain exhibited more spindle MT signals than plo1s, indicating that mutations in the C-terminal domain of Asp1 cause spindle MT stabilisation (Fig. 3D-G). These data suggested that bypass of Plo1 essentiality is achieved by increasing MT stability and/or generation.

\section{Glucose limitation bypasses Plo1 essentiality}

The mechanism by which glucose limitation recovers the viability of plo1 1 is not readily explainable. Glucose reduction did not appear to change Plo1-GFP localisation. Both in high $(3 \%)$ and low $(0.08 \%)$ glucose media, Plo1-GFP was localised to SPBs from prophase to metaphase and delocalised at anaphase (Fig. S4A, B). To observe the process of mitosis, we followed Alp6 ${ }^{\mathrm{GCP} 3}$-GFP and spindle MTs in double ght5 5 plo1 $\Delta$ (Ght5 is a glucose transporter). Interestingly, Alp6 ${ }^{\mathrm{GCP} 3}$-GFP accumulation at the SPB and spindle MT abundance were restored in the double mutant (Fig. 4A-D). MTs appeared to be more stable in $g h t 5 \Delta$, as incomplete disassembly of interphase MTs was often observed at the onset of mitosis, which reflected more total mCherry signals in the mutant than in the wild-type (arrows in Fig. 4B). Consistent with this observation, ght5 $\Delta$ conferred resistance to TBZ (Fig. S3D). 
Next, we tested the localisation of Mid1 ${ }^{\text {anillin, }}$, which is recruited to the equatorial region during mitosis and defines the division site, depending on phosphorylation by Plo1 (47). We observed that Mid1 was not properly localised to the cortex in the viable ght5 $\Delta$ plo1 $\Delta$ strain, whereas the cortical localisation was normal in single ght5 (Fig. 4E-G). Consistent with this observation, the septum was mislocalised in $g h t 5 \Delta$ plol $\Delta$, similar to mid $1 \Delta$ (Fig. S4C-E). The results revealed that the septation error was not directly linked to the lethality of plols. Cdc $7^{\text {Hippo }}$ is another downstream factor of Plo1; the SPB localisation of $\mathrm{Cdc} 7^{\text {Hippo }}$ during metaphase, but not telophase, is impaired in the plo1

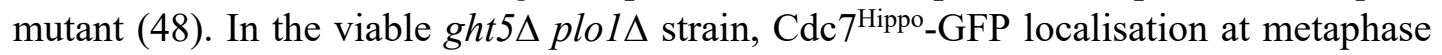
SPB was not detectable (Fig. 4H, I). These results indicated that not all Plo1 downstream events, including the phosphorylation of the direct substrate, are restored by ght 5 mutations.

\section{Casein kinase 1 (CK1) constitutes a masked mechanism for spindle bipolarisation}

Since proteins in the glucose-PKA pathway are not SPB- or spindle-associated, we hypothesised that other pathways are enhanced when glucose is limited, which promotes $\gamma$-TuRC localisation. To identify the effector proteins in such pathways, we performed a genetic screening, with the aim to acquire mutants that were synthetic lethal with double ght $5 \Delta$ plol $\Delta$ or $p k a 1 \Delta$ plol $\Delta$. For this, we first transformed a plasmid containing the lo $^{+}$ gene in the double mutants, conducted mutagenesis, and selected the strains that could not lose the plasmid (Fig. 5A). A total of 13 mutants were identified that were synthetic

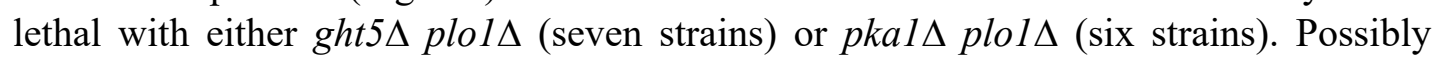
responsible genes were selected based on sequencing (e.g. dramatic amino acid changes, nonsense mutations, or identified in multiple strains). Synthetic lethality was confirmed for five genes (bubl, hhpl, imll, makl, and wis 1$)$ and one gene ( $\sin 1)$ by gene disruption and crossing with ght $5 \Delta$ plol $\Delta$ and pkals plols, respectively. However, two mutants (imll and wisl) and one mutant $(\sin 1)$ resulted in poor growth when singly combined with ght $5 \Delta$ and pkal $\Delta$, respectively. These were excluded from further analysis because the major basis of synthetic lethality may not involve the lack of Plo1 kinase. makl

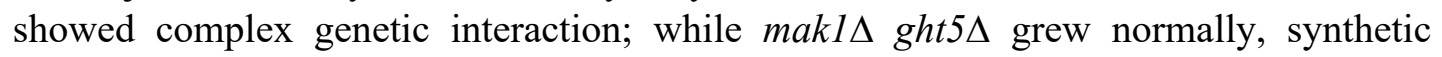
lethality was revealed when mCherry-tubulin was introduced. In addition, the double makl $\Delta$ pkal $\Delta$ grew poorly in the absence of mCherry-tubulin expression. Therefore, this gene was also excluded from further analyses. In contrast, triple disruption was not selected for two other genes, bubl and $h h p l$ (Fig. S5A, B), whereas the double mutants with $g h t 5 \Delta$ grew in a manner indistinguishable from the single ght $5 \Delta$ even in the presence of mCherry-tubulin. We further confirmed the synthetic lethality of $h \mathrm{hpl} 1 \Delta$ with other PKA-pathway genes git $1 \Delta$ plol $\Delta$ and pkal 1 plol $1 \Delta$ (Fig. S5C, D). Thus, bubl and hhpl were essential for plol $1 \Delta$ viability.

To identify the lethal event caused by these mutations, we observed live cells of the triple disruptants, bubl $1 \Delta$ ght $5 \Delta$ plol $\Delta$ and $h h p 1 \Delta$ ght $5 \Delta$ plol $\Delta$. For this, we selected each triple disruptant that possessed the Plo1-GFP multicopy plasmid. Viable cells were cultured in non-selective medium, by which cells naturally lose the plasmid at a certain probability. Time-lapse images were then acquired. We analysed the cells that no longer had Plo1-GFP signals, as these cells represent triple gene disruptants. As a control, we prepared double ght5 plo1s possessing the Plo1-GFP plasmid and performed the identical 'plasmid loss' culture. In the control strain that had no GFP signals, monopolar 
spindles were converted into bipolar spindles within $30 \mathrm{~min}$, followed by entry into anaphase, in $>60 \%$ cells, as expected (Fig. 5B and E). In contrast, in triple bubl $\Delta$ ght $5 \Delta$ plo1 $\Delta$, anaphase began even when spindles were still monopolar in 13 out of 43 cells (Fig. 5C). This phenotype explains the lethality of the strain and is consistent with the fact that Bub1 is an integral component of the spindle assembly checkpoint, which prevents premature anaphase entry (49). In contrast, in $h$ hpl $\Delta$ ght $5 \Delta$ plol $\Delta,>80 \%$ of cells were arrested in monopolar states for $>30 \mathrm{~min}$, and spindle bipolarisation and anaphase entry were scarcely observed, similar to the plo $1 \Delta$ strain in the normal medium (Fig. 5D and E). We concluded that the lethality of $h h p 1 \Delta$ ght $5 \Delta$ plol $\Delta$ comes from a defect in spindle bipolarisation, similar to plol $\Delta$ in the normal medium.

hhpl encodes casein kinase I (CK1), which is distributed throughout the cell and is enriched at the SPB $(50,51)$. Hhp $1^{\mathrm{CK} 1}$ is involved in a variety of cellular processes, such as DNA repair, ubiquitination-dependent regulation of septation initiation, DNA recombination and cohesin removal during meiosis $(50,52-54)$. However, to the best of our knowledge, $\mathrm{Hhp} 1^{\mathrm{CK} 1}$ has not been directly linked to spindle function in fission yeast.

To investigate the basis of the unexpected genetic interaction, we first tested whether Hhp $1^{\mathrm{CK} 1}$ expression/localisation was altered by ght 5 disruption. To this end, we tagged GFP to Hhp $1^{\mathrm{CK} 1}$ in the wild-type and ght $5 \Delta$ backgrounds. Time-lapse mitosis imaging and GFP intensity quantification indicated that $\mathrm{Hhp} 1^{\mathrm{CK} 1}$ localisation was unchanged, but the overall abundance became more variable and on average slightly increased in the absence of $g h t 5(96 \pm 23,120 \pm 63[\mathrm{AU}, \pm \mathrm{SD}], \mathrm{n}=30$ each $)$. However, the level of $h h p 1$ mRNA was not elevated by a glucose reduction, suggesting that post-transcriptional regulation underlies the increased Hhp1 in the cell (Fig. S5E). Next, we tested whether

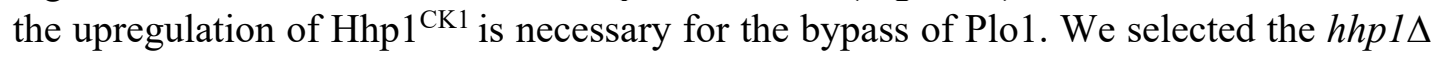
ght $5 \Delta$ plo1s triple disruptunt that possesses the Hhp $1^{\mathrm{CK} 1}$-GFP multicopy plasmid, and conducted a plasmid-loss experiment. In this experiment, GFP signal intensity served as an indicator of intracellular levels of the $\mathrm{Hhp} 1^{\mathrm{CK} 1}$ protein. Time-lapse imaging and subsequent image analysis showed that the level of the Hhp $1^{\mathrm{CK} 1}$ protein was overall correlated with the efficiency of spindle bipolarisation (Fig. 5G, 5H [grey vs. green]). However, the impact of the slight increase in $\mathrm{Hhp} 1^{\mathrm{CK} 1}$ observed in ght $5 \Delta$ was marginal; when we compared the time required for monopolar-to-bipolar conversion, we observed a slight and statistically nonsignificant decrease (Fig. $5 \mathrm{H}$ [grey vs. orange]). Thus, a moderate increase in $\mathrm{Hhp} 1^{\mathrm{CK} 1}$ facilitates bipolar spindle formation in the absence of Plo1 and Ght5, although it may not be a prerequisite for BOE.

Next, we investigated whether ectopic expression of Hhp $1^{\mathrm{CK} 1}$ was sufficient for the recovery of plo1s viability. We tested the expression of $\mathrm{Hhp}^{\mathrm{CK} 1}$ by two different promoters on the multicopy plasmid, but we could not obtain data that reproducibly showed that Hhp $1^{\mathrm{CK} 1}$ expression restored plo1 $\Delta$ colonies (Fig. S5F). In addition, Hhp $1^{\mathrm{CK} 1}$ expression from the plasmid did not enhance the growth of alp6-V664F plo1 $\Delta$ or alp4D440E plo1 $\Delta$, which was viable on its own but had slower growth than the wild-type (Fig. $\mathrm{S} 5 \mathrm{~F})$. Thus, an increase in $\mathrm{Hhp} 1^{\mathrm{CK} 1}$ levels alone did not increase the fitness of plo1 $\Delta$ and was insufficient for the bypass of Plo1 essentiality.

Finally, we observed spindle dynamics in the hhpl single disruptant. Most of the cells $(99 \%)$ assembled bipolar spindles, and mitosis proceeded comparably to the wildtype. However, among the 272 cells monitored, we found that 3 cells $(1 \%)$ formed monopolar spindles; this was not observed in our imaging of control Hhp $1^{\mathrm{CK} 1}+$ cells $(\mathrm{N}$ 


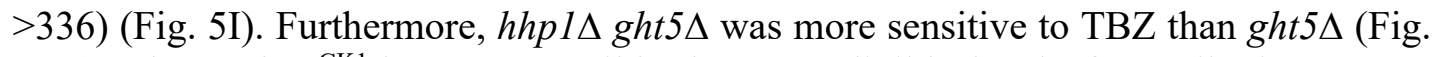
S3D). Thus, Hhp $1^{\mathrm{CK} 1}$ has a very mild, almost negligible level of contribution to MT stability and bipolar spindle assembly in the presence of Plo1, but becomes essential in the absence of Plo1. In S. pombe, $h h p 2^{+}$also encodes CK1 (52). Therefore, we selected the hhp $1 \Delta$ hhp $2 \Delta$ double disruptant expressing mCherry-tubulin and Alp6 ${ }^{\mathrm{GCP} 3}$-GFP, and performed time-lapse microscopy. Interestingly, monopolar spindles appeared at a much higher frequency than single $\operatorname{hhp} 1 \Delta(29 \%, \mathrm{n}=79)$ (Fig. 5I). Other phenotypes, such as undeveloped spindle MTs, were also observed in the double disruptant (Fig. 5I, right). We further determined if $h h p 2 \Delta$ would be synthetically lethal with three viable plol $\Delta$

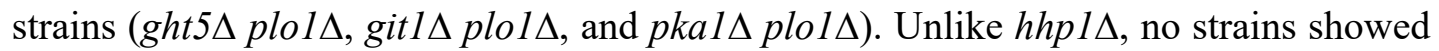
synthetic lethality with $h h p 2 \Delta$. Thus, Hhp1 $1^{\mathrm{CK} 1}$ and $\mathrm{Hhp} 2^{\mathrm{CK} 1}$ were not completely redundant for bypass-related functions, which corroborates the previous report that they are different in subcellular localisation and abundance (51).

\section{Masked contribution of CK1 to spindle formation in a human colon cancer cell line}

Among the four Plks in mammals, Plk1 is required for centrosome maturation and bipolar spindle formation in many cell types and is thus most analogous to S. pombe Plo1. There are also several CK1 family members in mammals. As CK1 $\delta$ is localised at the centrosome $(55,56)$, we tested whether CK $1 \delta$ constitutes the masked mechanism behind Plk1 in human cells (Fig. 6). The treatment of a human colon cancer line (HCT116) with a low concentration $(3 \mathrm{nM})$ of Plk1 inhibitor BI2536 resulted in a slightly higher frequency of monopolar spindle appearance in early prometaphase (Fig. 6A and B). PF670462, an inhibitor of CK1 $\delta / \varepsilon(57,58)$, did not increase the number of monopolar spindles. However, when both inhibitors were simultaneously treated, $36 \%$ of the cells first assembled monopolar spindles (Fig. 6A and B). The monopolar spindles were eventually converted to bipolar spindles; however, this process required $>30 \mathrm{~min}$ in $\sim 20 \%$ of the cells when two compounds were simultaneously added (Fig. 6C). These results highlight the importance of CK1, perhaps $\mathrm{CK} 1 \delta$, in spindle bipolarisation in human colon cancer cells, when Plk1 function is partially impaired.

\section{Discussion}

This study represents a rare example of the experimental BOE of genes required for mitosis. The BOE occurrence in Plo1 was unexpected, as it has been recognised as a versatile, essential kinase in mitosis not only in animal cells but also in fission yeast. However, there is evolutionary evidence supporting that this gene can be deletable; for example, plants have lost Plks, whereas the ancestral algae possess Plks (59). In our initial BOE screening using plo1s spores, only one viable strain was recovered, in which the gene encoding the glucose transporter Ght 5 was lost through a deletion event. Subsequent evolutionary repair (experimental evolution) experiments led to the identification of more mutations, many of which restored viability of plols without the ght 5 mutation. Thus, the initial mutagenesis-based screen was not sensitive enough to capture all the possible BOE. More BOE may be uncovered in the yeast system, including BOE-M, by applying more sensitive methods, or simply by increasing the screen scale.

Plo1 loss can be rendered non-lethal by mutations in several genes, some of which were unrelated to each other and not associated with spindle functions at first glance. 
371 However, this is in accordance with many previous examples of BOE or evolutionary

372 repair in the laboratory, where compensatory mutations are often found in genes outside 373 of the perturbed functional module (3). Subsequent analysis suggested that bypass 374 mutations converge into a common outcome: the increase in spindle MTs. This was 375 achieved by multiple direct and indirect mechanisms, such as mutations in an MT 376 destabiliser and MT nucleator, or through glucose starvation. In contrast, the septum phenotype was not rescued in a viable strain. Thus, although multiple defects have been identified in the plol mutants, MT formation is directly linked to viability. In a broader sense, BOE analysis could be used to distinguish between essential and non-essential 380 functions of an essential gene.

The bypass of Plo1 essentiality by glucose reduction in the medium is intriguing from multiple perspectives. First, it illustrates the non-absolute nature of gene essentiality (1). If the low-glucose medium was used as the standard yeast culture medium, then Plo1 would have been assigned as a non-essential gene in $S$. pombe. Second, a change in available nutrients occurs, perhaps frequently, in the natural yeast habitat. The decrease in available glucose allows the yeast to lose a critical mitotic kinase and develop an alternative mechanism. The data support the theory that environmental change combined with gene mutations drives molecular diversity, namely, variation in genes required for an essential process (3). Third, the change in fundamental metabolism alters the expression of many genes (60), offering a unique 'genetic background' that is not achieved by mutations in a few mitotic genes. In the case of plols, a critical factor for survival was Hhp $1^{\mathrm{CK} 1}$. Because Hhp $1^{\mathrm{CK} 1}$ is SPB-associated, it is possible that critical Plo1 substrates (such as $\gamma$-TuRC or its associated factor) are phosphorylated by Hhp $1^{\mathrm{CK} 1}$. However, CK1 is unlikely the sole element of BOE based on glucose repression and other factors should be also involved, as Hhp $1^{\mathrm{CK} 1}$ overexpression alone was not sufficient to restore the viability of plols (Fig. 7). Interestingly, S. cerevisiae Hrr25 ${ }^{\mathrm{CK} 1}$ can phosphorylate and activate the $\gamma$-tubulin complex in vitro and this phosphorylation is required for in vivo $\gamma$-tubulin functions (61). Whether Hrr2 $5^{\mathrm{CK} 1}$ constitutes a masked mechanism of $\mathrm{Cdc}^{\text {Plk1 }}$ in $S$. cerevisiae is an intriguing question for future investigation.

$\mathrm{BOE}$, or synthetic viability, is a critical challenge in cancer chemotherapy because of the emergence of resistance (62). Plk inhibitors have been recognised as promising antitumor drugs $(21,23)$. However, our study suggests that there may be resistant cells involving CK1 and that double inhibition of Plk1 and CK1 $\delta$ may be more suitable for mitotic cell perturbation.

\section{Materials and methods}

409 We followed Takeda et al. (2019) for the yeast culture and gene disruption. Complete 410 medium YE5S contained 1\% yeast extract and 3\% (w/v) glucose, supplemented with 411 adenine, leucine, histidine, uracil, and lysine, whereas glucose was reduced to $0.02 \%$ in 412 the low-glucose medium. Synthetic PMG and EMM media were used when selection was 413 based on adenine, leucine or uracil. Cells were cultured at $32^{\circ} \mathrm{C}$ (plate) or $30^{\circ} \mathrm{C}$ (liquid), 414 unless other temperatures are indicated. Sporulation was induced in an SPA plate. Gene 415 disruption, site-directed mutagenesis, and GFP/mCherry tagging were performed using 416 the standard one-step replacement method (i.e. homologous recombination). 417 Transformation was performed using the conventional LiAc/PEG method (63), and 
418 targeted integration was confirmed by PCR. Selection of the strain after random spore or 419 transformation was based on leucine, uracil, G418 $(100 \mu \mathrm{g} / \mathrm{mL})$, hygromycin $(50 \mu \mathrm{g} / \mathrm{mL})$, 420 clonNAT $(100 \mu \mathrm{g} / \mathrm{mL})$, or blasticidin S deaminase $(37.5 \mu \mathrm{g} / \mathrm{mL})$. The strains, plasmids, 421 and primers used in this study are listed in Tables S1, S2, and S3, respectively.

422

423

424

425

426

427

428

429

430

431

432

433

434

435

436

437

438

439

440

441

442

443

444

445

446

447

448

449

450

451

452

453

454

455

456

457

458

459

460

461

462

463

464

\section{Human cell culture}

The human colon cancer-derived HCT116 line, in which the endogenous TubG1 gene $(\gamma-$ tubulin) was tagged with mClover, was cultured in McCoy's 5A medium (Gibco) supplemented with $10 \%$ serum and $1 \%$ antibiotics (64). Plk1 inhibitor BI2536 (3 nM) and CK1 inhibitor PF670462 $(2 \mu \mathrm{M})$ were treated for 24-30 h prior to imaging, whereas 30 nM BI2536 was added at the beginning of imaging. MTs were stained with $50 \mathrm{nM} \mathrm{SiR}-$ tubulin for $2 \mathrm{~h}$ prior to imaging; this concentration of SiR-tubulin did not significantly affect MT growth and nucleation in this cell line (64).

\section{BOE screening and confirmation}

We followed the method described by Takeda et al. (2019). The initial screening encompassing eight mitotic gene disruptants was performed for $1 \times 10^{7}$ spores, and plol screening was repeated with a larger scale $\left(8 \times 10^{7}\right.$ spores $)$. One or 11 viable colonies were obtained for plol in the respective screening, for which PCR confirmed that the strain was indeed deleted from the entire plol open reading frame (ORF). One of the viable plo1 $\Delta$ strains was crossed with the wild-type (975 or 972), followed by sporulation on an SPA plate. The spores were incubated in YE5S with G418 $(100 \mu \mathrm{g} / \mathrm{mL})$ and cycloheximide $(100 \mu \mathrm{g} / \mathrm{mL})$ plates. The viable colonies were subjected to WGS (i.e. bulk segregant analysis). Analysis of the genome sequence of the strain identified a unique $\sim 7$ $\mathrm{kb}$ deletion on chromosome III, in which three genes, SPCC1235.17, SPCC1235.18, and ght5, were included. By crossing other lines with the Ght5-GFP integrant strain (24), we observed a strong genetic link for six of the strains (one strain was sterile and was not analysed further). Sequencing of the three strains verified that all had mutations or deletions in the ght 5 locus; one showed a mutation from TGG to TAG that introduced a premature stop codon in $g h t 5$ and another showed $\operatorname{Gln}^{152}$ to Pro substitution of ght5. To confirm this suppression, the ght 5 gene was independently deleted by homologous recombination, and the growth of ght $5 \Delta$ plol $\Delta$ cells was investigated using a spot test. WGS of the other three plol $\Delta$ revertants identified other suppressor candidates (the other line was sterile and was not further analysed). One strain had TT instead of AC in the nggl coding region, which introduces a premature stop codon. Ngg1 (also called Ada3) is a component of the SAGA complex (65). To investigate whether the mutations in $n g g l$ rescue plol lethality, a genetic linkage test was conducted with the rec6 gene, which is located close to $n g g l$. The other two revertants had mutations in the cyrl gene (encoding adenylate cyclase, a component of the PKA pathway). Nucleotide insertion in cyrl of one strain caused a frameshift that induced a premature stop codon, whereas the other strain had an amino acid change from Asn to Lys. Therefore, the plol $\Delta$ rescue ability by pkal or cyrl deletion was tested. The strains lacking both pkal and plol or cyrl and plol grew on $3 \%$ glucose medium, albeit slower than the wild-type.

\section{Whole genome sequencing}

Approximately $2 \times 10^{8}$ cells were harvested, and their genomic DNA was extracted using Dr. GenTLE (Takara). The genomic DNA was sequenced by BGI, Novogene, or the gene 
sequencing facility at Nagoya University, where the read length of the sequence was 150 $\mathrm{bp}$ or $81 \mathrm{bp}$. The FASTQ file was modified and mapped using CLC genomic workbench software. The ends ( $5 \mathrm{bp}$ from the $5^{\prime}$ end and $1 \mathrm{bp}$ from the $3^{\prime}$ end) of each fragment were trimmed, and these fragments were then filtered for a minimum sequencing quality of 30 datasets to reduce the error ratio. The fragments were aligned to the $S$. pombe genome reference and formatted as BAM files. IGV was used to visualise the BAM file and check the mutation site. Insertion, deletion, single nucleotide variation (SNV), and large indels were investigated. All the WGS data are available at Sequence Read Archive (SRA) at NCBI (accession number: PRJNA768628).

\section{Experimental evolution}

Experimental evolution was conducted with serial dilution and saturation (66). Saturated culture after passage $(10 \mathrm{~mL})$ was 1,000-fold diluted for the next passage. After culturing for 150-200 generations, cell cultures were spread onto agar plates, and the fastest growing colonies were selected for each culture. In the first round, six plo1 $\Delta$ colonies were inoculated into $0.08 \%$ glucose liquid medium with $\mathrm{G} 418(10 \mu \mathrm{g} / \mathrm{mL}$; in order to avoid microbial contamination) and cultured at $30^{\circ} \mathrm{C}$. Eventually, six independent colonies were picked up (hereafter called ' $1{ }^{\text {st }} \mathrm{EVO}$ ' strains). They showed faster colony growth on $0.08 \%$ glucose agar plate than the original plols strain. Three of them also formed small colonies on the normal $3 \%$ glucose medium. These strains were further subjected to experimental evolution using 3\% glucose medium with G418 $(10 \mu \mathrm{g} / \mathrm{mL})$ at $30^{\circ} \mathrm{C}$ (two or three independent cultures). In the end, eight 'evolved' strains (i.e. the fastest growing strains) were obtained as plol $\Delta$ second-round evolution strains (hereafter called $\left.2^{\text {nd }} E V O\right)$. Another round of experimental evolution $\left(3^{\text {rd }} E V O\right)$ was carried out for

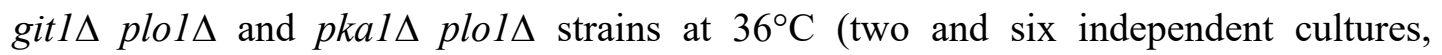
respectively), as these formed tiny colonies at $36^{\circ} \mathrm{C}$, whereas the plol $1 \Delta$ strain did not grow even in the low-glucose medium at this high temperature. We determined the genome sequences and identified the specific mutations in five out of six strains from $1^{\text {st }}$ EVO, including three strains for which $2^{\text {nd }} E V O$ selection was carried out, and six out of eight strains from $2^{\text {nd }} E V O$. On average, we found 2.2 mutations introduced in the open reading frame. Three out of the five $1^{\text {st }}$ EVO strains had a point mutation in SAGA complex genes (spt20, sgf73, and spt7). Mutations in glucose transporters or PKApathway genes ( $g h t 5$, git5, gitl, and ght 8 ) were found in four of the six $2^{\text {nd }}$ EVO strains. From the $3^{\text {rd }}$ EVO, we sequenced the three fastest growing clones and found aspl mutations in two strains and tral (SAGA) in the third strain.

\section{Synthetic lethality screening}

Double disruptants ght $5 \Delta$ plol $\Delta$ and pkals plols were transformed with the Plo1 plasmid (ura $4+)$. Cells $\left(5 \times 10^{4}-1 \times 10^{6}\right.$ cells) were mutagenised with UV (150 or 200 $\times 100 \mu \mathrm{J} / \mathrm{CM}^{2}$; UVP Crosslinker CL-1000) and plated onto a PMG (ura4-) plate. After 6 $\mathrm{d}$, the colonies were replica plated onto YE5S plates. After $2 \mathrm{~d}$, the colonies were replica plated onto 5-FOA and PMG (ura4-) plates. Cells that could not survive in the absence of the plasmid were isolated (inviable colonies after replica plating onto $2 \mathrm{mg} / \mathrm{mL} 5$-FOAcontaining plates). For one of the obtained strains, the genomic DNA library (pTN-L1, NBRP) was transformed into the strain, and the colonies found on 5-FOA plates were isolated. The plasmid extracted from the colonies was sequenced and found to encode $h h p 1^{+}$. However, this method did not work well for other strains. Therefore, for the other 
51212 strains, whole genome sequences were determined and candidate mutations

513 (nonsynonymous and frameshift) were inspected by independent deletion and crossing.

514

515

516

517

518

519

520

521

522

523

524

525

526

527

528

529

530

531

532

533

534

535

536

537

538

539

540

541

542

543

544

545

546

547

548

549

550

551

552

553

554

555

556

557

\section{Microscopy}

Exponentially growing yeast cells or spores were attached to a $1 \mu \mathrm{g} / \mathrm{mL}$ lectin-coated glass plate for $>10 \mathrm{~min}$ at $32^{\circ} \mathrm{C}(67)$. Live imaging was performed with a spinning-disc confocal microscope (Nikon Ti; 100× $1.45 \mathrm{NA}$ ) with a perfect focus system. The cells were maintained at $32^{\circ} \mathrm{C}$ in a stage-top heater. Images were taken using an ImagEM CCD camera (Hamamatsu) every $1-3$ min for exponentially growing cells or every 1 or 2 min for germinating spores (z-stacks: $1 \mu \mathrm{m} \times 5$ sections). Spores were pre-incubated for 10 $12 \mathrm{~h}$ in 3\% YE5S medium before imaging. For imaging that involved plasmid loss, cells were pre-incubated overnight in $\mathrm{PMG}$ without uracil or leucine and exponentially growing cells were transferred to $3 \%$ YE5S medium for $\sim 24 \mathrm{~h}$ prior to microscopy. Human cell live imaging was performed with a spinning-disc confocal microscope (Nikon Ti; 40× $1.45 \mathrm{NA}$ ) with a perfect focus system. Images were captured using an ImagEM CCD camera (Hamamatsu). The cells were maintained at $37^{\circ} \mathrm{C}$ in a stage-top heater, where $\mathrm{CO}_{2}$ was supplied. Z-stack images ( $3 \mu \mathrm{m} \times 5$ sections) were taken every 3 min. Images were analysed using FIJI, and the data were plotted using GraphPad Prism software. The signal intensity of mCherry-tubulin on the spindle and Hhpl-GFP in late G2 was measured after maximum projection, whereas a single focal plane was selected for Alp6-GFP and Cut7-GFP measurements. Two Alp6-GFP signals on the bipolar spindles were summed to obtain the total intensity. The maximum projection images are presented in the figures.

\section{Real time PCR}

Exponentially growing yeast cells were lysed with zymolyase (50 U per $1 \times 10^{7}$ cells), and total RNA samples were prepared using the RNeasy Plant Mini kit (Qiagen), using the yeast protocol described in the manufacturer's instructions of RNeasy Mini Kit (Qiagen). To eliminate genomic DNA contamination, an additional DNase treatment was performed using an RNase-free DNase Set (Qiagen). PrimeScript II (Takara) was used for the reverse transcription. Real-time PCR was performed and analysed using Step One Plus (Applied Biosystems) with SYBR Green Master Mix (Applied Biosystems). The primer set designed at the C-terminus of actl was used as the control (24). The copy number of $h h p l$ mRNA relative to act 1 was calculated from a standard curve drawn using serial dilutions of cDNA as the templates.

\section{Statics}

All statistical analyses were performed using the GraphPad Prism software. Two-way ANOVAs were applied between the two groups in Fig. 3B, 3C, 3G, 4C, 4D, and 5F, and a two-way ANOVA with multiple comparisons using Tukey's test to compare the four groups in Fig. 2H and a one-way ANOVA with multiple comparisons using Tukey's test to compare the four groups (Fig. $5 \mathrm{H}$ ). The data distribution was assumed to be normal, but this was not formally tested. Established $\mathrm{P}$ values were denoted as follows: $\mathrm{P}>0.05$ (ns), $\mathrm{P}<0.05(*), \mathrm{P}<0.01(* *), \mathrm{P}<0.001(* * *)$, and $\mathrm{P}<0.0001(* * * *)$. Error bars in the graph represent the SEM or SD of each group. Experiments were performed twice or more, and the data from one experimental set were presented after quantitative analysis, 
except for Fig. 4C, 4D, 5G, 5H, and 6C, where the data from multiple experiments were combined because of insufficient sample numbers in a single experiment.

\section{Acknowledgements}

We are grateful to Aoi Takeda for help with the experimental evolution culture; Shigeaki Saitoh (Kurume University), Kojiro Takeda (Konan University), Masamitsu Sato (Waseda University), Iain Hagan (University of Manchester), Ye Dee Tay (University of Edinburgh), and National Bio-Resource Project (NBRP) of the MEXT, Japan, for yeast strains and plasmids; Kazuma Uesaka for help with sequence analysis; Ken Sawin, Hiro Ohkura, and Ye Dee Tay (University of Edinburgh) for valuable discussions and protocols; Rie Inaba, Kyoko Zenbutsu, and Miki Ueda for media preparation; Shigeaki Saitoh and Moé Yamada for comments on the manuscript. This work was supported by JSPS KAKENHI (19K22383) to G.G. and JST SPRING to J.K. The authors declare no conflicts of interest.

\section{References}

1. Rancati G, Moffat J, Typas A, \& Pavelka N (2018) Emerging and evolving concepts in gene essentiality. Nat Rev Genet 19(1):34-49.

2. Ryan CJ, Krogan NJ, Cunningham P, \& Cagney G (2013) All or nothing: protein complexes flip essentiality between distantly related eukaryotes. Genome Biol Evol 5(6):1049-1059.

3. LaBar T, Phoebe Hsieh YY, Fumasoni M, \& Murray AW (2020) Evolutionary Repair Experiments as a Window to the Molecular Diversity of Life. Curr Biol 30(10):R565-R574.

4. van Leeuwen J, et al. (2020) Systematic analysis of bypass suppression of essential genes. Mol Syst Biol 16(9):e9828.

5. Liu G, et al. (2015) Gene Essentiality Is a Quantitative Property Linked to Cellular Evolvability. Cell 163(6):1388-1399.

6. Li J, et al. (2019) Systematic analysis reveals the prevalence and principles of bypassable gene essentiality. Nat Commun 10(1):1002.

7. Takeda A, Saitoh S, Ohkura H, Sawin KE, \& Goshima G (2019) Identification of 15 New Bypassable Essential Genes of Fission Yeast. Cell Struct Funct 44(2):113-119.

8. Sonnichsen B, et al. (2005) Full-genome RNAi profiling of early embryogenesis in Caenorhabditis elegans. Nature 434(7032):462-469.

9. Neumann B, et al. (2010) Phenotypic profiling of the human genome by timelapse microscopy reveals cell division genes. Nature 464(7289):721-727.

10. McKinley KL \& Cheeseman IM (2017) Large-Scale Analysis of CRISPR/Cas9 Cell-Cycle Knockouts Reveals the Diversity of p53-Dependent Responses to Cell-Cycle Defects. Dev Cell 40(4):405-420 e402.

11. Conduit PT, Wainman A, \& Raff JW (2015) Centrosome function and assembly in animal cells. Nat Rev Mol Cell Biol 16(10):611-624.

12. Yamada M \& Goshima G (2017) Mitotic Spindle Assembly in Land Plants: Molecules and Mechanisms. Biology (Basel) 6(1). 
604

605

606

607

608

609

610

611

612

613

614

615

616

617

618

619

620

621

622

623

624

625

626

627

628

629

630

631

632

633

634

635

636

637

638

639

640

641

642

643

644

645

646

647

648

13. Gourguechon S, Holt LJ, \& Cande WZ (2013) The Giardia cell cycle progresses independently of the anaphase-promoting complex. J Cell Sci 126(Pt 10):22462255.

14. Vale RD (2003) The molecular motor toolbox for intracellular transport. Cell 112(4):467-480.

15. Leong SY, Edzuka T, Goshima G, \& Yamada M (2020) Kinesin-13 and Kinesin8 Function during Cell Growth and Division in the Moss Physcomitrella patens. Plant Cell 32(3):683-702.

16. Hara M, Ariyoshi M, Okumura EI, Hori T, \& Fukagawa T (2018) Multiple phosphorylations control recruitment of the KMN network onto kinetochores. Nat Cell Biol 20(12):1378-1388.

17. Malvezzi F, et al. (2013) A structural basis for kinetochore recruitment of the Ndc80 complex via two distinct centromere receptors. EMBO J 32(3):409-423.

18. Yukawa M, Ikebe C, \& Toda T (2015) The Msd1-Wdr8-Pkl1 complex anchors microtubule minus ends to fission yeast spindle pole bodies. J Cell Biol 209(4):549-562.

19. Syrovatkina V \& Tran PT (2015) Loss of kinesin-14 results in aneuploidy via kinesin-5-dependent microtubule protrusions leading to chromosome cut. Nat Commun 6:7322.

20. Olmsted ZT, Colliver AG, Riehlman TD, \& Paluh JL (2014) Kinesin-14 and kinesin-5 antagonistically regulate microtubule nucleation by gamma-TuRC in yeast and human cells. Nat Commun 5:5339.

21. Otto T \& Sicinski P (2017) Cell cycle proteins as promising targets in cancer therapy. Nat Rev Cancer 17(2):93-115.

22. Archambault V \& Glover DM (2009) Polo-like kinases: conservation and divergence in their functions and regulation. Nat Rev Mol Cell Biol 10(4):265-275.

23. Cunningham CE, et al. (2020) The CINs of Polo-Like Kinase 1 in Cancer. Cancers (Basel) 12(10).

24. Saitoh S, et al. (2015) Mechanisms of expression and translocation of major fission yeast glucose transporters regulated by CaMKK/phosphatases, nuclear shuttling, and TOR. Mol Biol Cell 26(2):373-386.

25. Grant PA, Winston F, \& Berger SL (2021) The biochemical and genetic discovery of the SAGA complex. Biochim Biophys Acta Gene Regul Mech 1864(2):194669.

26. Byrne SM \& Hoffman CS (1993) Six git genes encode a glucose-induced adenylate cyclase activation pathway in the fission yeast Schizosaccharomyces pombe. J Cell Sci 105 ( Pt 4):1095-1100.

27. Maeda T, Watanabe Y, Kunitomo H, \& Yamamoto M (1994) Cloning of the pka1 gene encoding the catalytic subunit of the cAMP-dependent protein kinase in Schizosaccharomyces pombe. J Biol Chem 269(13):9632-9637.

28. Shashkova S, Welkenhuysen N, \& Hohmann S (2015) Molecular communication: crosstalk between the Snf1 and other signaling pathways. FEMS Yeast Res 15(4):fov026.

29. Klip A, Tsakiridis T, Marette A, \& Ortiz PA (1994) Regulation of expression of glucose transporters by glucose: a review of studies in vivo and in cell cultures. FASEB J 8(1):43-53. 
660

661

662

663

664

665

666

667

668

669

670

671

672

673

674

675

676

677

678

679

680

681

682

683

684

685

686

687

688

689

690

691

692

693

694

695

30. Kelkar M \& Martin SG (2015) PKA antagonizes CLASP-dependent microtubule stabilization to re-localize Pom1 and buffer cell size upon glucose limitation. Nat Commun 6:8445.

31. Liu P, Wurtz M, Zupa E, Pfeffer S, \& Schiebel E (2021) Microtubule nucleation: The waltz between gamma-tubulin ring complex and associated proteins. Curr Opin Cell Biol 68:124-131.

32. Lenart $\mathrm{P}$, et al. (2007) The small-molecule inhibitor BI 2536 reveals novel insights into mitotic roles of polo-like kinase 1. Curr Biol 17(4):304-315.

33. Tanaka K, et al. (2001) The role of Plo1 kinase in mitotic commitment and septation in Schizosaccharomyces pombe. EMBO J 20(6):1259-1270.

34. Bahler J, et al. (1998) Role of polo kinase and Mid1p in determining the site of cell division in fission yeast. J Cell Biol 143(6):1603-1616.

35. Walde S \& King MC (2014) The KASH protein Kms2 coordinates mitotic remodeling of the spindle pole body. J Cell Sci 127(Pt 16):3625-3640.

36. Ohkura H, Hagan IM, \& Glover DM (1995) The conserved Schizosaccharomyces pombe kinase plo1, required to form a bipolar spindle, the actin ring, and septum, can drive septum formation in G1 and G2 cells. Genes Dev 9(9):1059-1073.

37. Grallert A, et al. (2013) Centrosomal MPF triggers the mitotic and morphogenetic switches of fission yeast. Nat Cell Biol 15(1):88-95.

38. Tallada VA, Tanaka K, Yanagida M, \& Hagan IM (2009) The S. pombe mitotic regulator Cut12 promotes spindle pole body activation and integration into the nuclear envelope. J Cell Biol 185(5):875-888.

39. Bridge AJ, Morphew M, Bartlett R, \& Hagan IM (1998) The fission yeast SPB component Cut12 links bipolar spindle formation to mitotic control. Genes Dev 12(7):927-942.

40. Hagan I \& Yanagida M (1990) Novel potential mitotic motor protein encoded by the fission yeast cut7+ gene. Nature 347(6293):563-566.

41. Paoletti A, et al. (2003) Fission yeast cdc31p is a component of the half-bridge and controls SPB duplication. Mol Biol Cell 14(7):2793-2808.

42. West RR, Vaisberg EV, Ding R, Nurse P, \& McIntosh JR (1998) cut11(+): A gene required for cell cycle-dependent spindle pole body anchoring in the nuclear envelope and bipolar spindle formation in Schizosaccharomyces pombe. Mol Biol Cell 9(10):2839-2855.

43. Bestul AJ, Yu Z, Unruh JR, \& Jaspersen SL (2021) Redistribution of centrosomal proteins by centromeres and Polo kinase controls partial nuclear envelope breakdown in fission yeast. Mol Biol Cell 32(16):1487-1500.

44. Flory MR, Morphew M, Joseph JD, Means AR, \& Davis TN (2002) Pcplp, an Spc110p-related calmodulin target at the centrosome of the fission yeast Schizosaccharomyces pombe. Cell Growth Differ 13(2):47-58.

45. Vardy L \& Toda T (2000) The fission yeast gamma-tubulin complex is required in $\mathrm{G}(1)$ phase and is a component of the spindle assembly checkpoint. EMBO J 19(22):6098-6111.

46. Pohlmann J, et al. (2014) The Vip1 inositol polyphosphate kinase family regulates polarized growth and modulates the microtubule cytoskeleton in fungi. PLoS Genet 10(9):e1004586.

47. Almonacid M, et al. (2011) Temporal control of contractile ring assembly by Plo1 regulation of myosin II recruitment by Mid1/anillin. Curr Biol 21(6):473-479. 
48. Wachowicz P, et al. (2015) Analysis of S. pombe SIN protein association to the SPB reveals two genetically separable states of the SIN. J Cell Sci 128(4):741754.

49. Bernard P, Hardwick K, \& Javerzat JP (1998) Fission yeast bub1 is a mitotic centromere protein essential for the spindle checkpoint and the preservation of correct ploidy through mitosis. J Cell Biol 143(7):1775-1787.

50. Johnson AE, Chen JS, \& Gould KL (2013) CK1 is required for a mitotic checkpoint that delays cytokinesis. Curr Biol 23(19):1920-1926.

51. Elmore ZC, Guillen RX, \& Gould KL (2018) The kinase domain of CK1 enzymes contains the localization cue essential for compartmentalized signaling at the spindle pole. Mol Biol Cell 29(13):1664-1674.

52. Dhillon N \& Hoekstra MF (1994) Characterization of two protein kinases from Schizosaccharomyces pombe involved in the regulation of DNA repair. EMBOJ 13(12):2777-2788.

53. Phadnis N, et al. (2015) Casein Kinase 1 and Phosphorylation of Cohesin Subunit Rec11 (SA3) Promote Meiotic Recombination through Linear Element Formation. PLoS Genet 11(5):e1005225.

54. Rumpf C, et al. (2010) Casein kinase 1 is required for efficient removal of Rec8 during meiosis I. Cell Cycle 9(13):2657-2662.

55. Greer YE \& Rubin JS (2011) Casein kinase 1 delta functions at the centrosome to mediate Wnt-3a-dependent neurite outgrowth. J Cell Biol 192(6):993-1004.

56. Greer YE, et al. (2014) Casein kinase 1delta functions at the centrosome and Golgi to promote ciliogenesis. Mol Biol Cell 25(10):1629-1640.

57. Aquino Perez C, Burocziova M, Jenikova G, \& Macurek L (2021) CK1-mediated phosphorylation of FAM110A promotes its interaction with mitotic spindle and controls chromosomal alignment. EMBO Rep 22(7):e51847.

58. Meng QJ, et al. (2010) Entrainment of disrupted circadian behavior through inhibition of casein kinase 1 (CK1) enzymes. Proc Natl Acad Sci U S A 107(34):15240-15245.

59. Okamura E, Sakamoto T, Sasaki T, \& Matsunaga S (2017) A Plant Ancestral Polo-Like Kinase Sheds Light on the Mystery of the Evolutionary Disappearance of Polo-Like Kinases in the Plant Kingdom. Cytologia 82(3):261-266.

60. Saitoh S \& Yanagida M (2014) Does a shift to limited glucose activate checkpoint control in fission yeast? FEBS Lett 588(15):2373-2378.

61. Peng Y, et al. (2015) Interaction of CK1delta with gammaTuSC ensures proper microtubule assembly and spindle positioning. Mol Biol Cell 26(13):2505-2518.

62. Ashworth A, Lord CJ, \& Reis-Filho JS (2011) Genetic interactions in cancer progression and treatment. Cell 145(1):30-38.

63. Moreno S, Klar A, \& Nurse P (1991) Molecular genetic analysis of fission yeast Schizosaccharomyces pombe. Methods Enzymol 194:795-823.

64. Tsuchiya K \& Goshima G (2021) Microtubule-associated proteins promote microtubule generation in the absence of gamma-tubulin in human colon cancer cells. J Cell Biol 220(12).

65. Ringel AE, Cieniewicz AM, Taverna SD, \& Wolberger C (2015) Nucleosome competition reveals processive acetylation by the SAGA HAT module. Proc Natl Acad Sci U S A 112(40):E5461-5470. 
742 66. Laan L, Koschwanez JH, \& Murray AW (2015) Evolutionary adaptation after crippling cell polarization follows reproducible trajectories. Elife 4.

744 67. Ashraf S, Tay YD, Kelly DA, \& Sawin KE (2021) Microtubule-independent movement of the fission yeast nucleus. J Cell Sci 134(6).

746 68. Matsuyama A, Shirai A, \& Yoshida M (2008) A series of promoters for constitutive expression of heterologous genes in fission yeast. Yeast 25(5):371376. 
bioRxiv preprint doi: https://doi.org/10.1101/2021.12.15.472863; this version posted December 16, 2021. The copyright holder for this preprint (which was not certified by peer review) is the author/funder, who has granted bioRxiv a license to display the preprint in

A perpetuity. It is made available under aCC-BY-NC 4.0 International license.
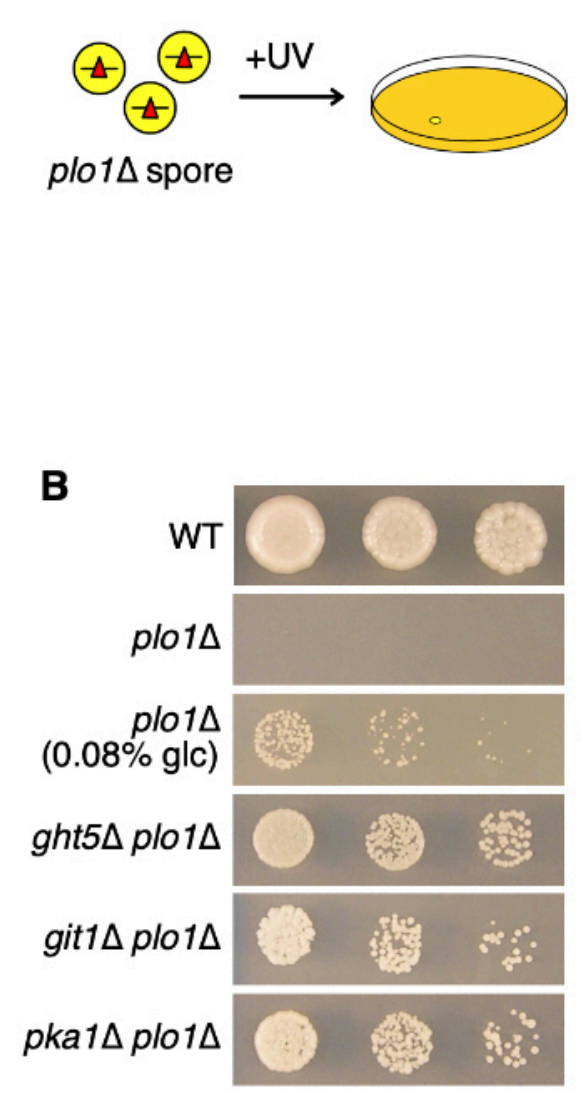
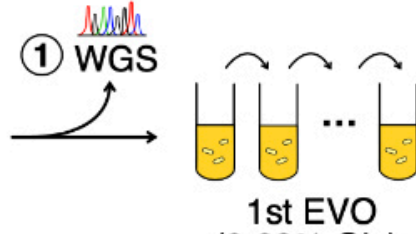

$(0.08 \% \mathrm{Glc})$
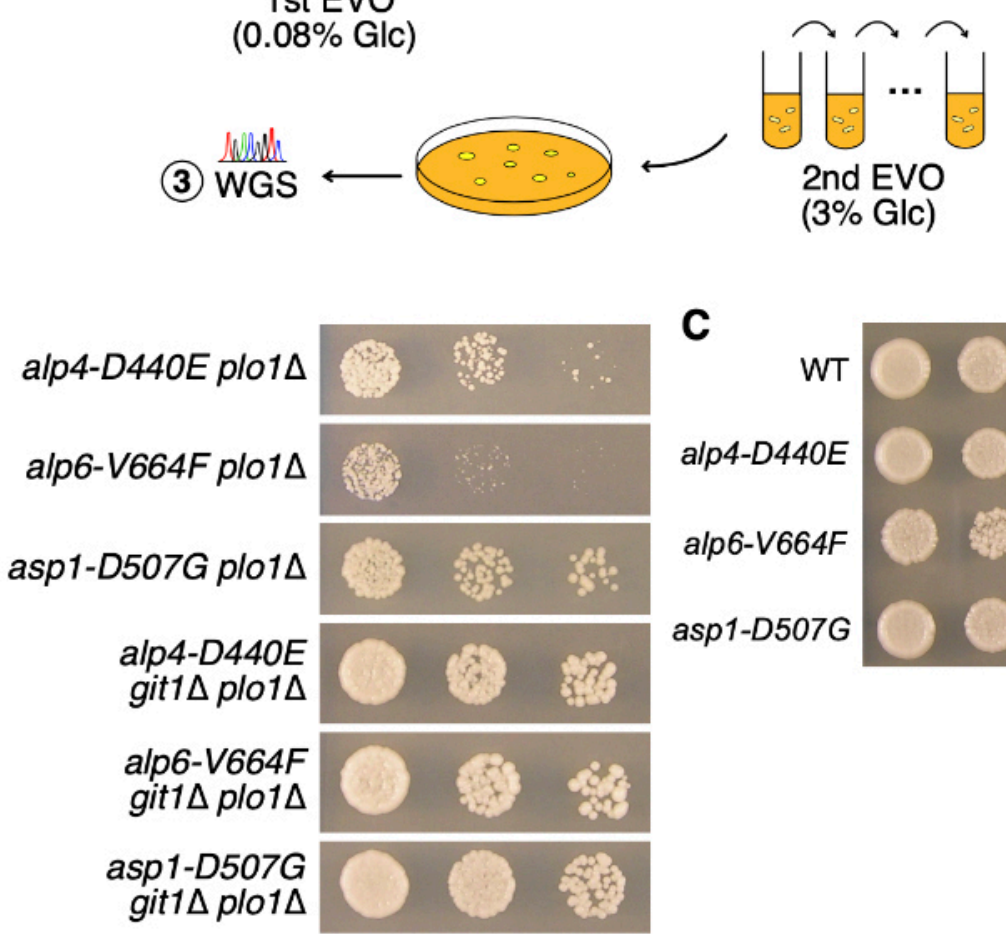

C WT

alp4-D440E

alp6-V664F

asp1-D507G

(2) WGS

(3\% Glc)

D

\begin{tabular}{|c|c|c|c|c|c|}
\hline Classification & Gene & Function and/or Orthologue & WGS & Mutation type & Rescue \\
\hline \multirow{6}{*}{$\begin{array}{c}\text { Glucose } \\
\text { /PKA }\end{array}$} & ght5 & Glucose transporter & $1 \& 3$ & Deletion, Frame shift & + \\
\hline & ght8 & Glucose transporter & 3 & Partial deletion & N.D. \\
\hline & git1 & & 3 & Frame shift & + \\
\hline & git5 & G protein beta & 3 & $\mathrm{H} 105 \mathrm{Y}$ & N.D. \\
\hline & cyr1 & Adenylate cyclase & 1 & N691K, Frame shift & + \\
\hline & pka1 & PKA & - & & + \\
\hline \multirow{3}{*}{$\begin{array}{l}\text { Microtubule } \\
\text { regulator }\end{array}$} & alp4 & GCP2(Y-TuRC) & 3 & D440E & + \\
\hline & alp6 & GCP3(Y-TuRC) & 2 & V664F & + \\
\hline & asp1 & PPIP5KNip1 & * & D507G, T575I & + \\
\hline \multirow{4}{*}{ SAGA } & spt7 & SUPT7L & 2 & $775-1 \mathrm{G}>\mathrm{T}$ & N.D. \\
\hline & spt20 & SUPT2OH & 2 & Frame shift & -+ \\
\hline & sgf73 & ATXN7 & 2 & C87F & N.D. \\
\hline & ngg1 & & 1 & E4D/Q5stop & + \\
\hline \multirow{3}{*}{ Others } & mip1 & RAPTOR (TOR pathway) & 3 & A1233S & + \\
\hline & ahk1 & MAP pathway scaffold protein & 3 & Frame shift & + \\
\hline & aps1 & Nudix hydrolase & 2 & Frame shift & + \\
\hline
\end{tabular}

${ }^{*} 36^{\circ} \mathrm{C}$ experimental evolution

\section{Figure 1. Isolation of viable plo1 $\Delta$ strains}

(A) Experimental procedure to isolate plo1 $\Delta$ strains. The yeast spores in which plo1 gene was replaced by drug-resistant cassette were mutagenised by UV and plated onto the drug-containing medium. The haploid colonies that appeared after several days represent the plo1 $\Delta$ strains. The whole genome sequence ('WGS') was determined to map the responsible suppressor mutations, while a few strains were subjected to experimental evolution (EVO), where serial dilution and saturation accumulated fitness-increasing mutations. EVO was repeated three times in different conditions, and suppressor mutations were determined by WGS. (B) Viable plo1 $\Delta$ strains obtained by indicated suppressor mutations. Cells $(5,000,1,000$, and 200) were spotted onto normal YE5S plates, except for the third row, where glucose (glc) concentration in the medium was reduced to $0.08 \%$ (YE5S, $4 \mathrm{~d}, 32^{\circ} \mathrm{C}$ ). (C) Single mutants of alp4-D440E, alp6-V664F, and asp1-D507G. Cells $\left(5,000,1,000\right.$, and 200) were spotted onto normal YE5S plates and incubated for $3 \mathrm{~d}$ at $32^{\circ} \mathrm{C}$. (D) List of suppressor mutations for plo1 $\Delta$. The 'WGS' column indicates at which step in (A) the mutation was identified. 'Rescue' column indicates whether the indicated mutation alone bypassed the essentiality of Plo1. The colony grew extremely poorly for the spt $20 \Delta$ plol $\Delta$ (marked with -+ ). 
bioRxiv preprint doi: https://doi.org/10.1101/2021.12.15.472863; this version posted December 16, 2021. The copyright holder for this preprint (which was not certified by peer review) is the author/funder, who has granted bioRxiv a license to display the preprint in

A
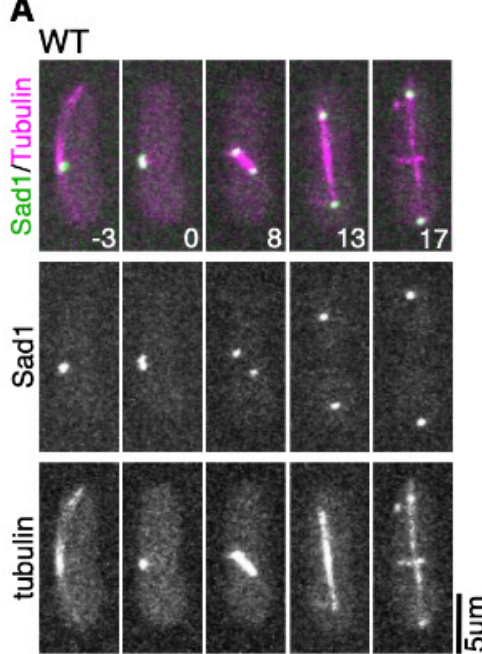

D
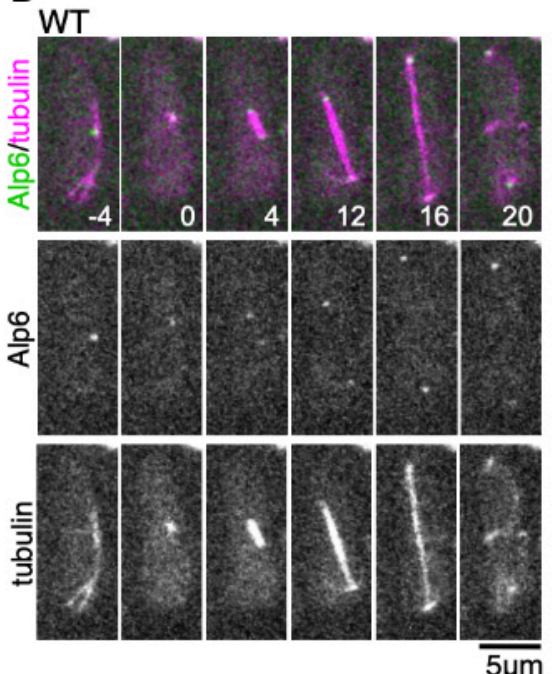

$$
\text { plo1s }
$$
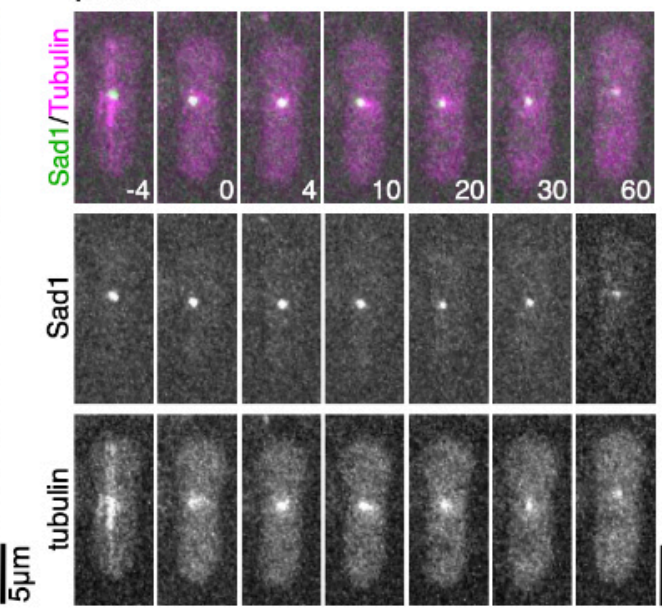

E

plo1s
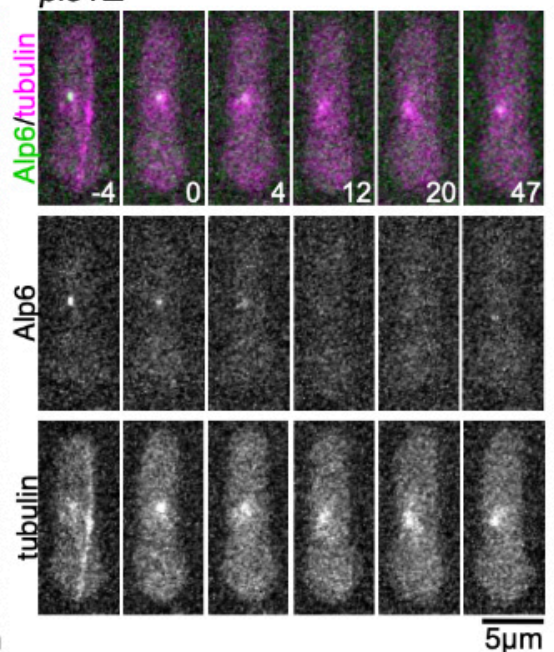

G

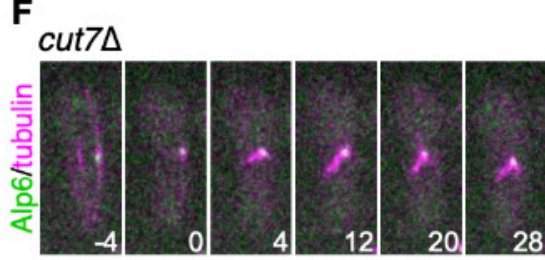

Gdc31
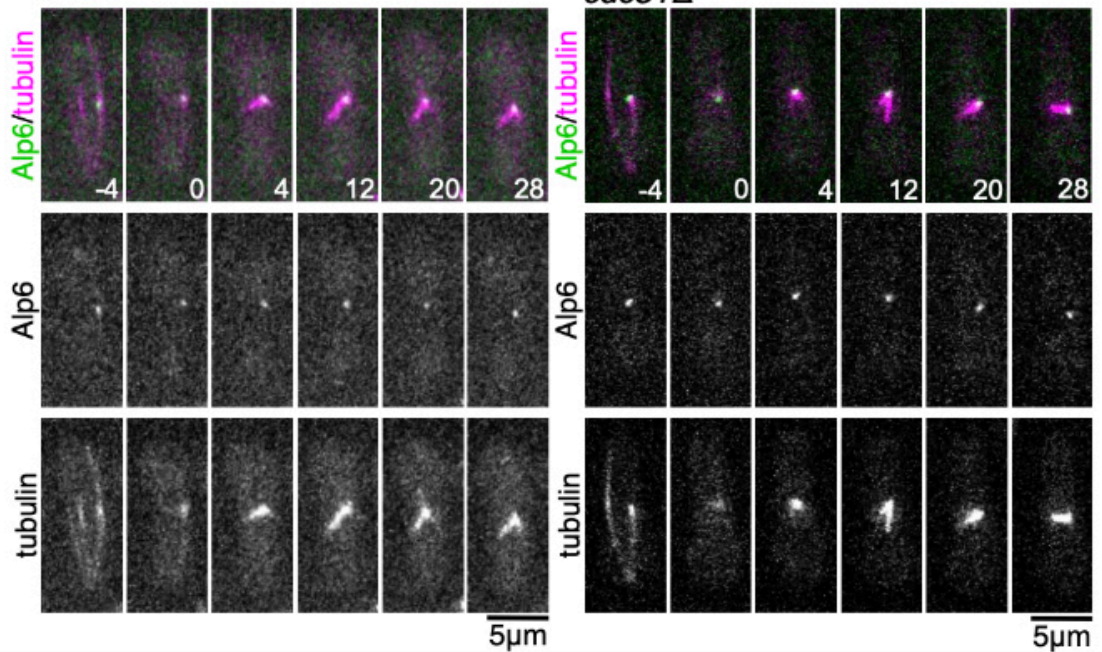

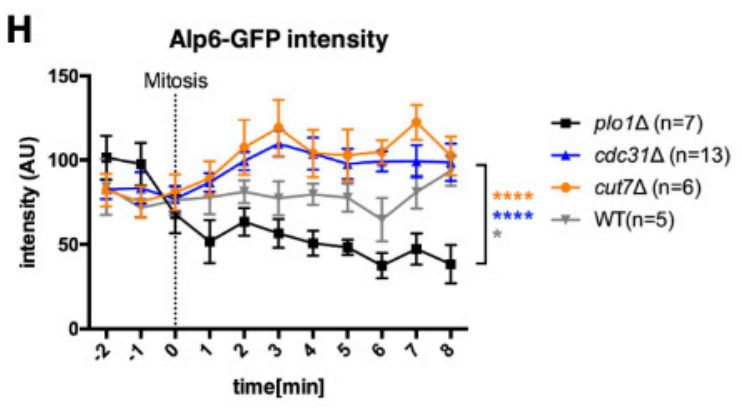

Figure 2. Monopolar spindle formation with reduced microtubules (MTs) and $\gamma$-TuRC localisation in plo1 $\Delta$

(A, B) Live imaging of the control and plols strains expressing Sad1 ${ }^{\text {SUN }}$-GFP and mCherry-tubulin. The first mitotic phase after spore germination was imaged. (C) Mitotic spindles of control and plo1 $\Delta$ strains expressing Sad1 ${ }^{\text {SUN }}$-GFP and mCherry-tubulin with longer exposure time. (D, E) Live imaging of the control and plo1 $\Delta$ strains expressing Alp6 ${ }^{\mathrm{GCP}}$-GFP and mCherry-tubulin. (F, G) Monopolar spindles of the $c u t 7 \Delta$ and $c d c 31 \Delta$ strains after germination. (H) Quantification of Alp6 $6^{\mathrm{GCP}}$-GFP intensity during mitosis. The signal intensities from 5 to 8 min were compared between the plol $\Delta$ and wild-type (WT), cut $7 \Delta$, or $\operatorname{cdc} 31 \Delta\left(* * * *, p<0.0001 ; *^{*}, \mathrm{p}=0.0226\right.$ ). Error bars indicate the standard error of the mean (SEM). Time $0(\mathrm{~min})$ was set at the onset of spindle formation. 
bioRxiv preprint doi: https://doi.org/10.1101/2021.12.15.472863; this version posted December 16, 2021. The copyright holder for this preprint (which was not certified by peer review) is the author/funder, who has granted bioRxiv a license to display the preprint in

A alp4-D440E plo1s

Type I (50\%)
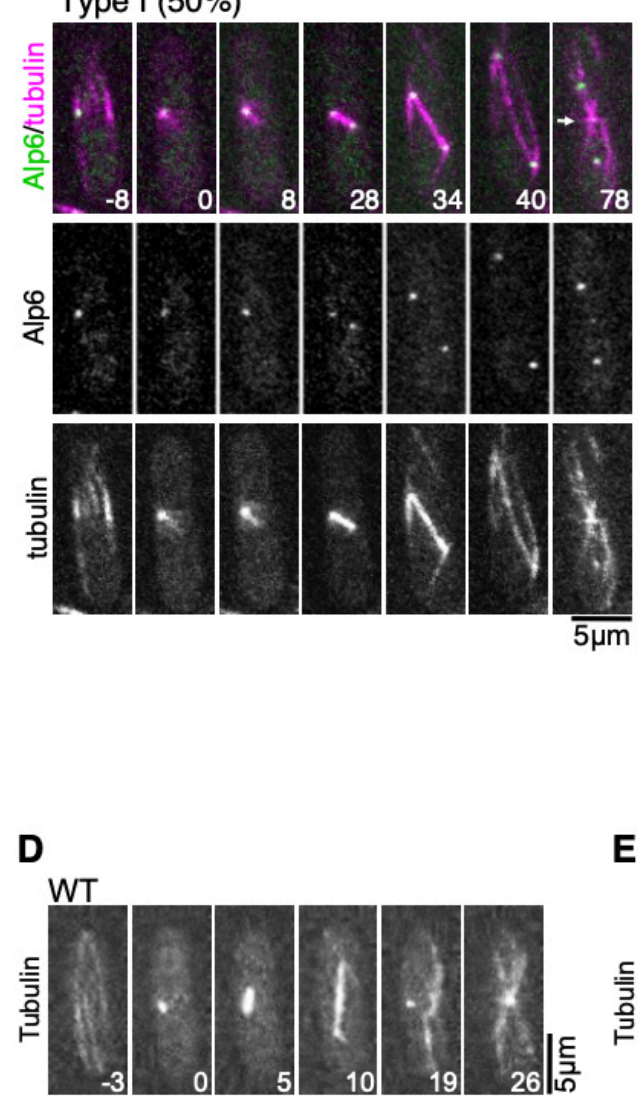

Type II (30\%)

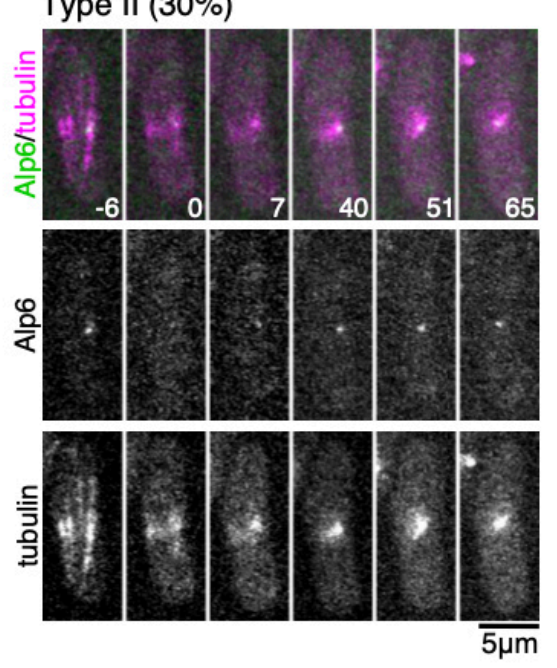

B

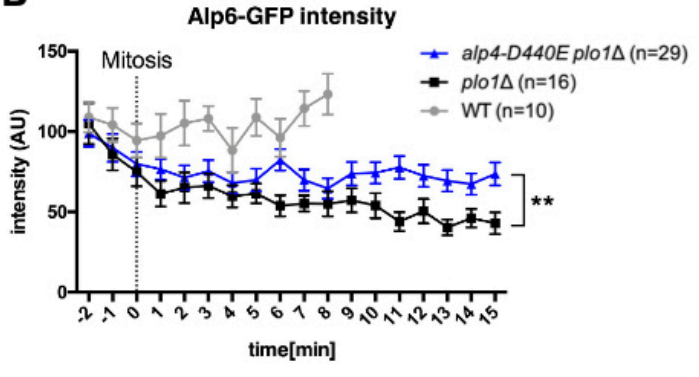

C mCherry-atb2

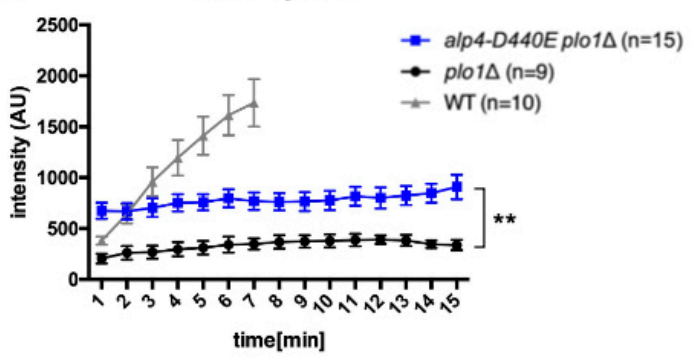

$\mathbf{F}$

asp1-D507G

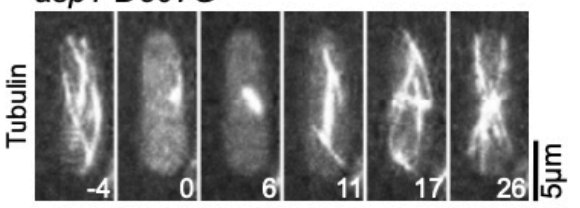

asp1-D507G plo1A

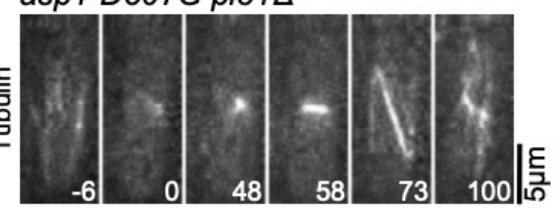

G mCherry-atb2

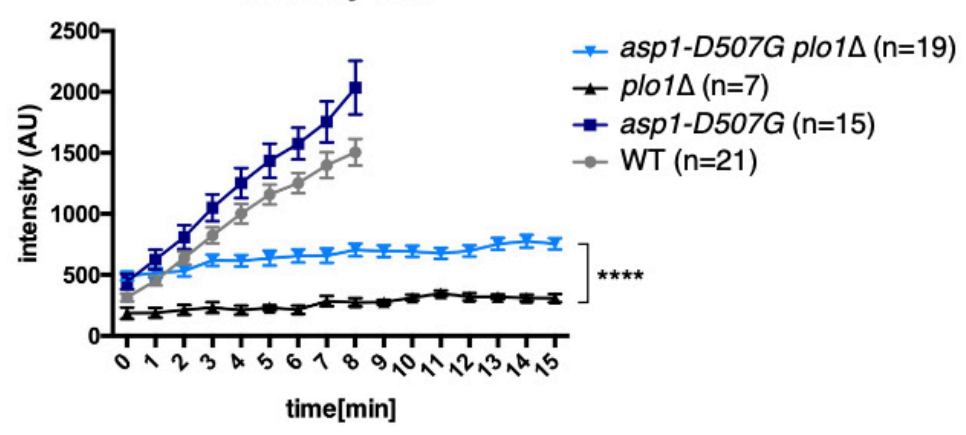

Figure 3. Microtubule (MT) nucleation and spindle bipolarisation were rescued by a point mutation in a $\gamma$-TuRC subunit or MT destabiliser

(A) (Left) Spindle bipolarisation after a prolonged monopolar state by a specific mutation in the alp $4^{G C P 2}$ gene. Equatorial MTs during telophase were also recovered (arrow at $78 \mathrm{~min}$ ). (Right) Failure in spindle bipolarisation. (B, C) Partial recovery of Alp6 ${ }^{\mathrm{GCP}}$-GFP and MT intensities by a specific mutation in the alp $4^{G C P 2}$ gene. The signal intensities from 12 to 15 min were compared between plol $\Delta$ and alp4-D440E plo1 $\Delta$; Alp6 ${ }^{\mathrm{GCP}}$-GFP intensity $(* *, \mathrm{p}=0.0049)$, and MT intensity $(* *, \mathrm{p}=0.0017)$. (D-G) Partial recovery of MT intensities

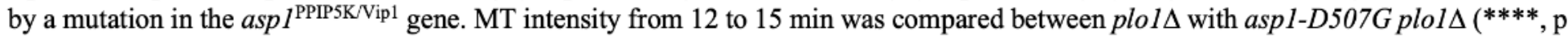
$<0.0001)$. In all the graphs, error bars indicate the standard error of the mean (SEM). Time 0 is set at the onset of spindle formation. Time 0 ( $\mathrm{min})$ is set at the onset of spindle formation. 
bioRxiv preprint doi: https://doi.org/10.1101/2021.12.15.472863; this version posted December 16, 2021. The copyright holder for this preprint (which was not certified by peer review) is the author/funder, who has granted bioRxiv a license to display the preprint in

A plo1s

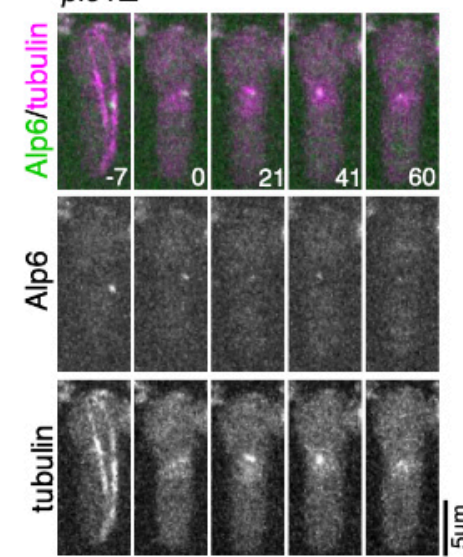

C

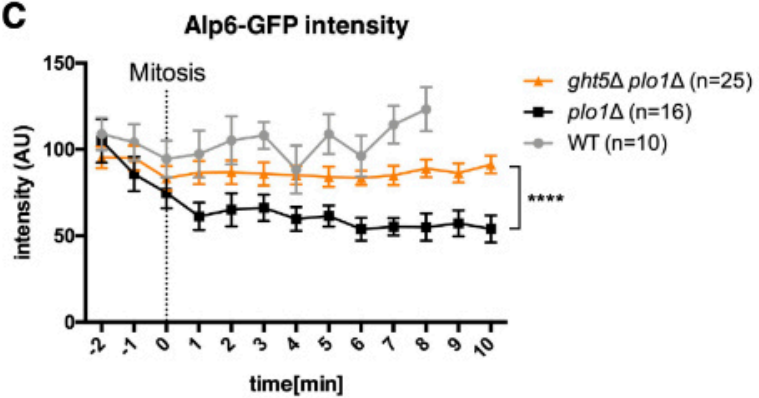
Bnade available under aCC-BY-NC 4.0 International license.
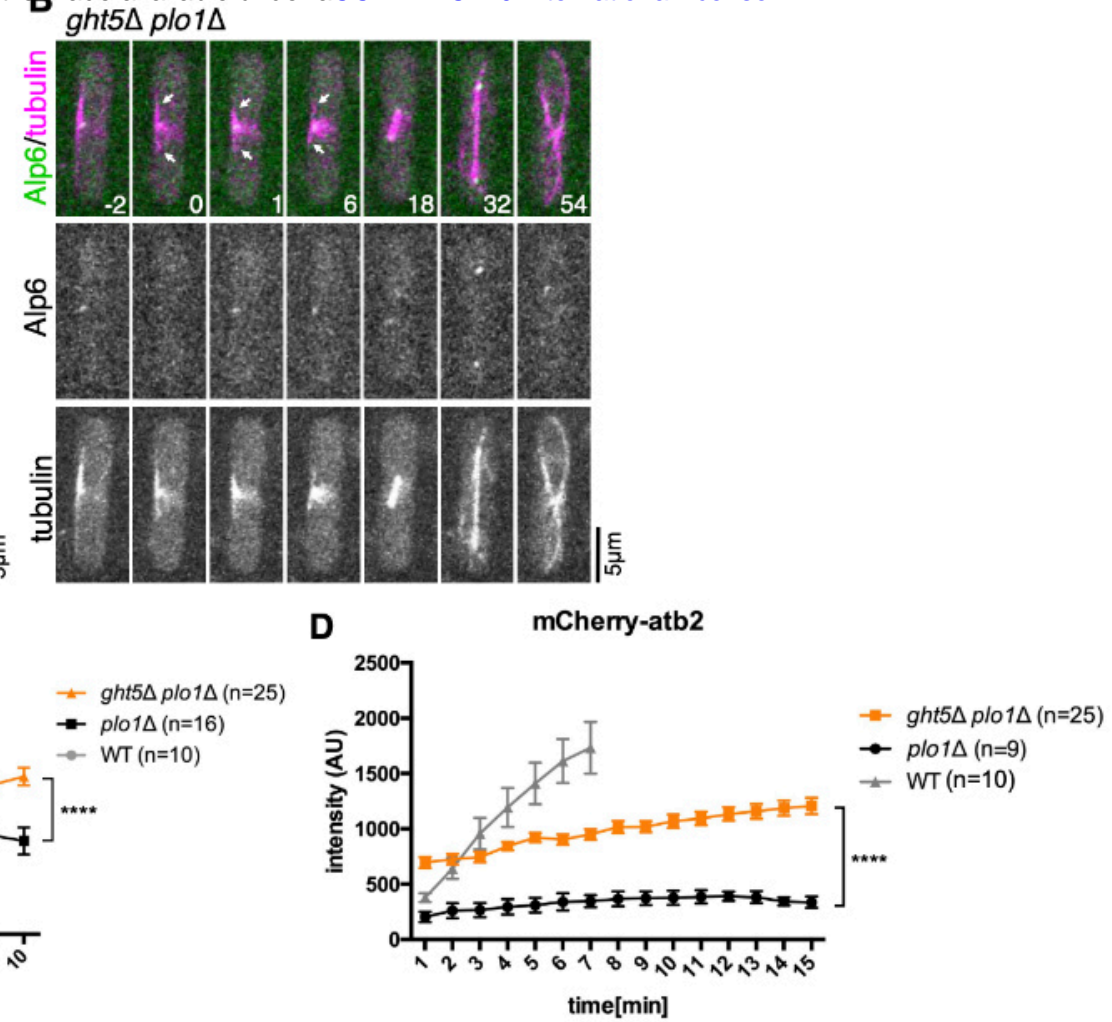

E

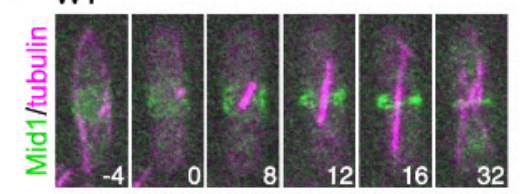

F $g h t 5 \Delta$

G ght5 $\Delta$ plo1 $\Delta$
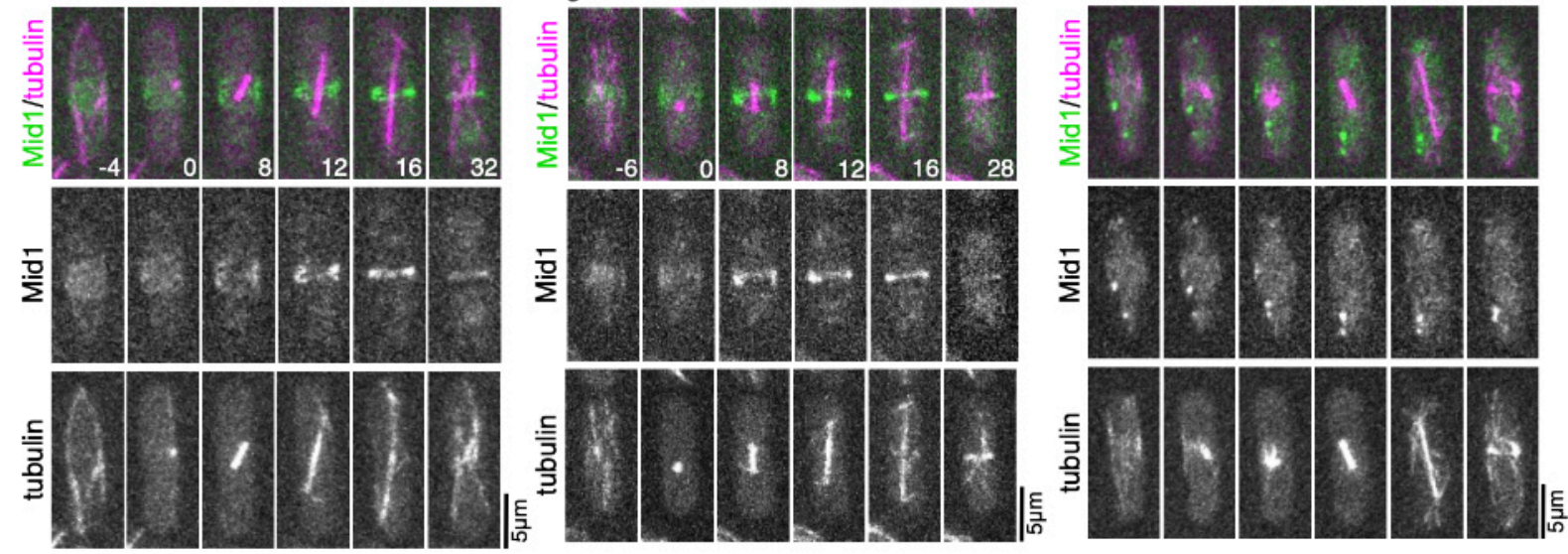

H WT

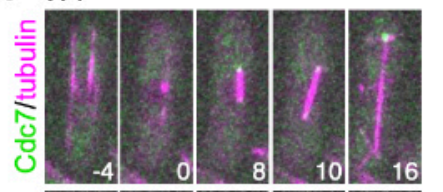

I ght5 $\Delta$ plo1 $\Delta$
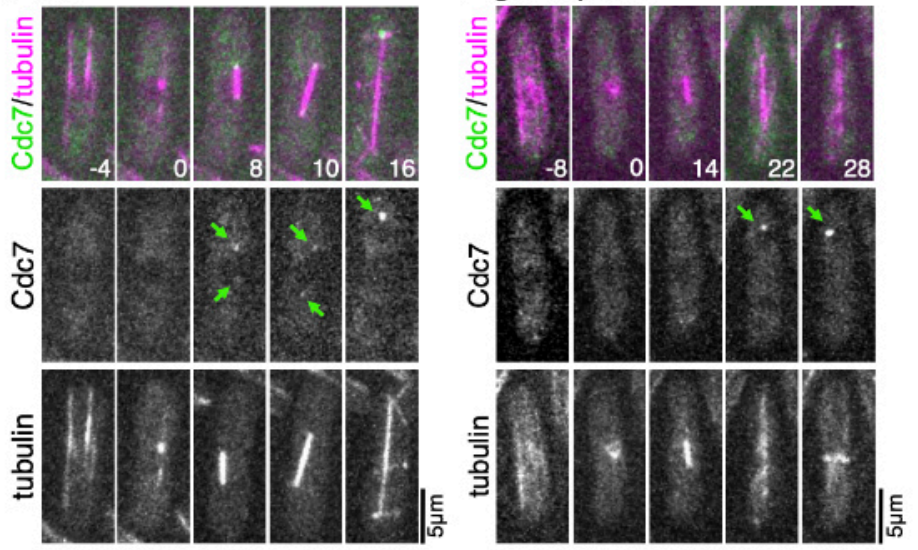

Figure 4. $\gamma$-TuRC localisation was restored by mutations in a glucose transporter in the absence of Plo1

(A) Live imaging of the plo $1 \Delta$ strain expressing Alp6 ${ }^{\mathrm{GCP} 3}$-GFP and mCherry-tubulin. The first mitotic phase after spore germination was imaged. (B) Live imaging of the ght $5 \Delta$ plo1 $\Delta$ strain expressing Alp6 ${ }^{\mathrm{GCP} 3}$-GFP and mCherry-tubulin. Mitosis in the exponentially growing phase was imaged. Arrows indicate interphase microtubules (MTs) that remain during spindle assembly. (C, D) Quantification of Alp6 ${ }^{\mathrm{GCP} 3}$-GFP and MT intensities during mitosis. The signal intensities were compared between plo1 $\Delta$ with $g h t 5 \Delta$ plo1 $\Delta$; Alp6 ${ }^{\mathrm{GCP} 3}$-GFP intensity from 7 to $10 \mathrm{~min}(* * * *, \mathrm{p}<0.0001)$ and MT intensity from 12 to $15 \mathrm{~min}(* * * *, \mathrm{p}<0.0001)$. Error bars indicate the standard error of the mean (SEM). Time 0 is set at the onset of spindle formation. Control data is identical to that in Fig. 2I and J. The increase in MT intensity during the early mitotic stage in ght $5 \Delta$ plol $\Delta$ is due to the incomplete disassembly of interphase MTs (see arrows in B). (E-

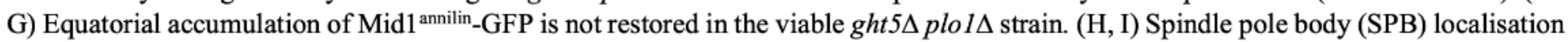

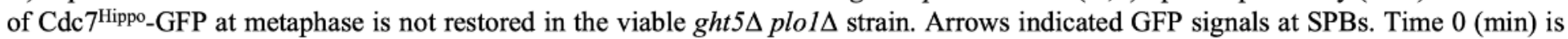
set at the onset of spindle formation. 
bioRxiv preprint doi: https://doi.org/10.1101/2021.12.15.472863; this version posted December 16, 2021. The copyright holder for this preprint (which was not certified by peer review) is the author/funder, who has granted bioRxiv a license to display the preprint in

A perpetuity. It is made available under aCC-BY-NC 4.0 International license.

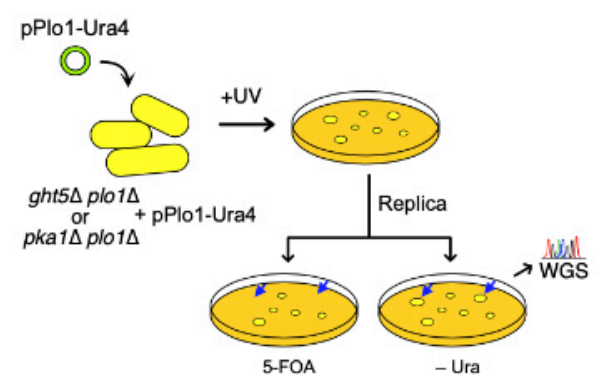

C

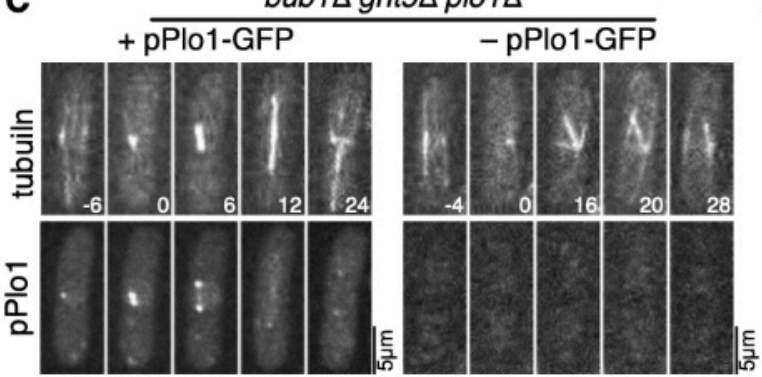

D

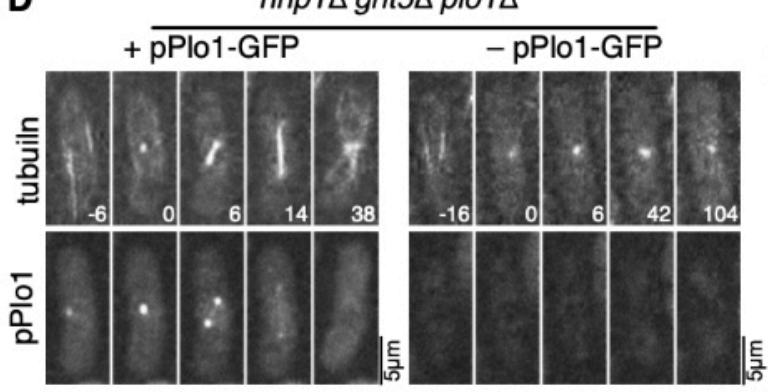

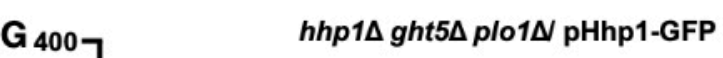

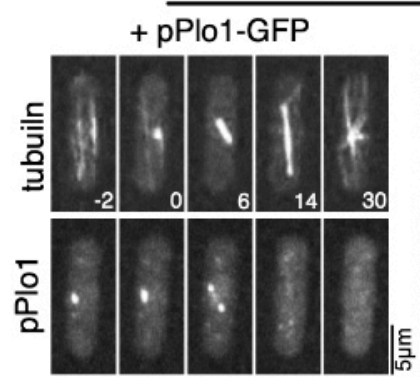

E
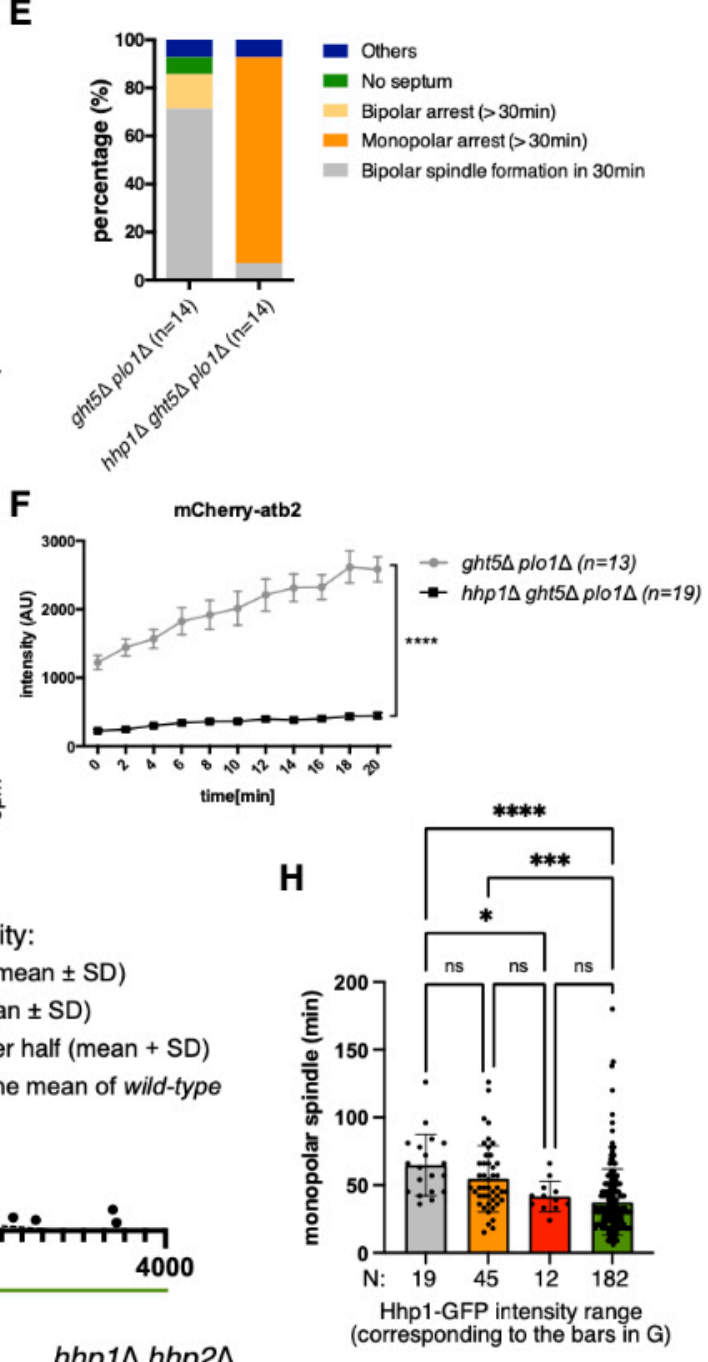

I cell phenotype
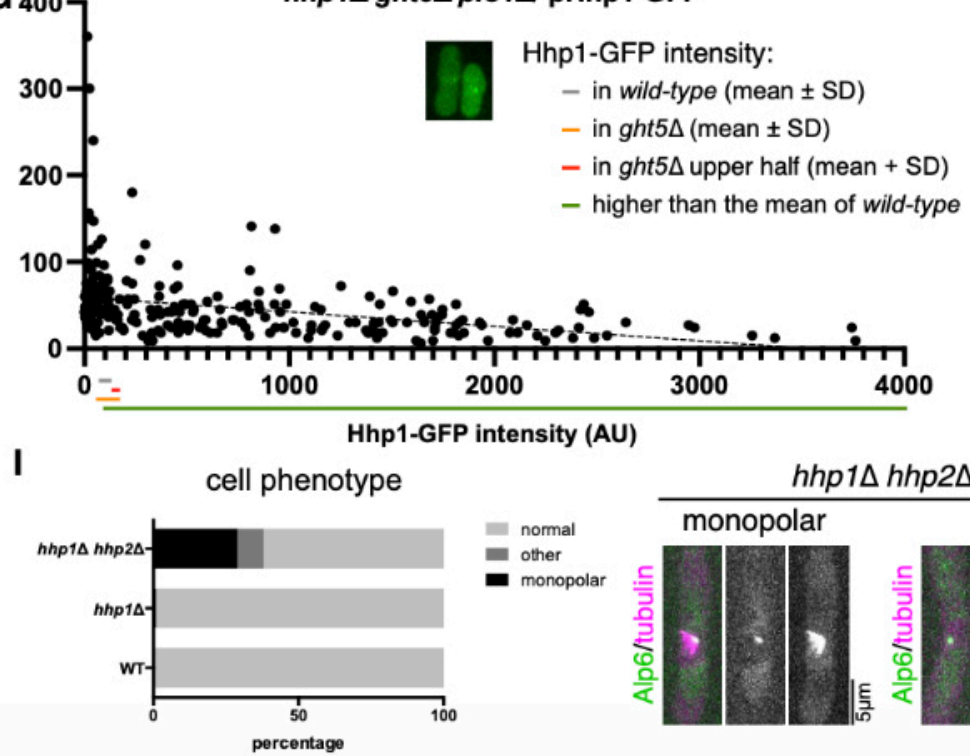

other

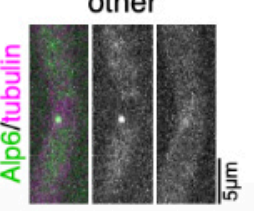

Figure 5. Hhp1 ${ }^{\mathrm{CK} 1}$ becomes essential for spindle formation in the absence of Plo1

(A) Schematic presentation of the synthetic lethal screening. The strain possessing Plol plasmid (ura4+) is sensitive to 5-FOA and therefore, does not grow. The strain that cannot grow specifically on the 5-FOA plate should have a mutation that is synthetic lethal with ght $5 \Delta$ plol $\Delta$ or pkal $\Delta$ plo1 $\Delta$. The genome sequences of these strains were determined ('WGS'). (B-D) Plasmid-loss experiment. The indicated double or triple disruptants transformed with Plo1-GFP plasmid were grown. Time-lapse imaging was performed and mitotic cells with or without Plo1-GFP signals were analysed. (E) Frequency of mitotic phenotypes (in the absence of Plo1-GFP). (F) MT intensity decreased in the absence of Hhp1 ${ }^{\mathrm{CK} 1}(* * * *, \mathrm{p}<0.0001)$. (G) Plasmid-loss experiment using a plol $\Delta$ ght $5 \Delta$ hhp $1 \Delta$ triple disruptant and multicopy Hhp1-GFP plasmid (leu+). Time spent with monopolar spindles was plotted for each cell. GFP intensity (arbitrary unit) corresponds to the amount of Hhp1 in a cell. Mean intensities ( \pm SD) of Hhp1-GFP signals in the wild-type background and ght5 $\Delta$ background were indicated by grey and orange bars, respectively. In this analysis, the mean background intensity of the parental strain that had no GFP expression (80.3 AU, $\mathrm{n}=31$ ) was subtracted from the Hhpl-GFP intensity value. (H) Time required for monopolar-tobipolar conversion. Three bars correspond to the samples with different GFP intensities described in $(\mathrm{G})$. Error bars represent SD $(*, \mathrm{p}=$ $0.0458 ; * * *, \mathrm{p}=0.0001 ; * * * *, \mathrm{p}<0.0001)$, and ns stands for "not significant." (I) A total of $29 \%$ of the $h h p 1 \Delta h h p 2 \Delta$ cells (n $=79$ ) and $1 \%$ of the hhpl $\Delta$ cells $(\mathrm{n}=272)$ assembled monopolar spindles, whereas this never occurred in control cells $(\mathrm{n}=336)$. A lack of spindle MTs was also observed in the double disruptant (right). Time 0 ( $\mathrm{min}$ ) was set at the onset of spindle formation. 
bioRxiv preprint doi: https://doi.org/10.1101/2021.12.15.472863; this version posted December 16, 2021. The copyright holder for this preprint (which was not certified by peer review) is the author/funder, who has granted bioRxiv a license to display the preprint in

A perpetuity. It is made available under aCC-BY-NC 4.0 International license.

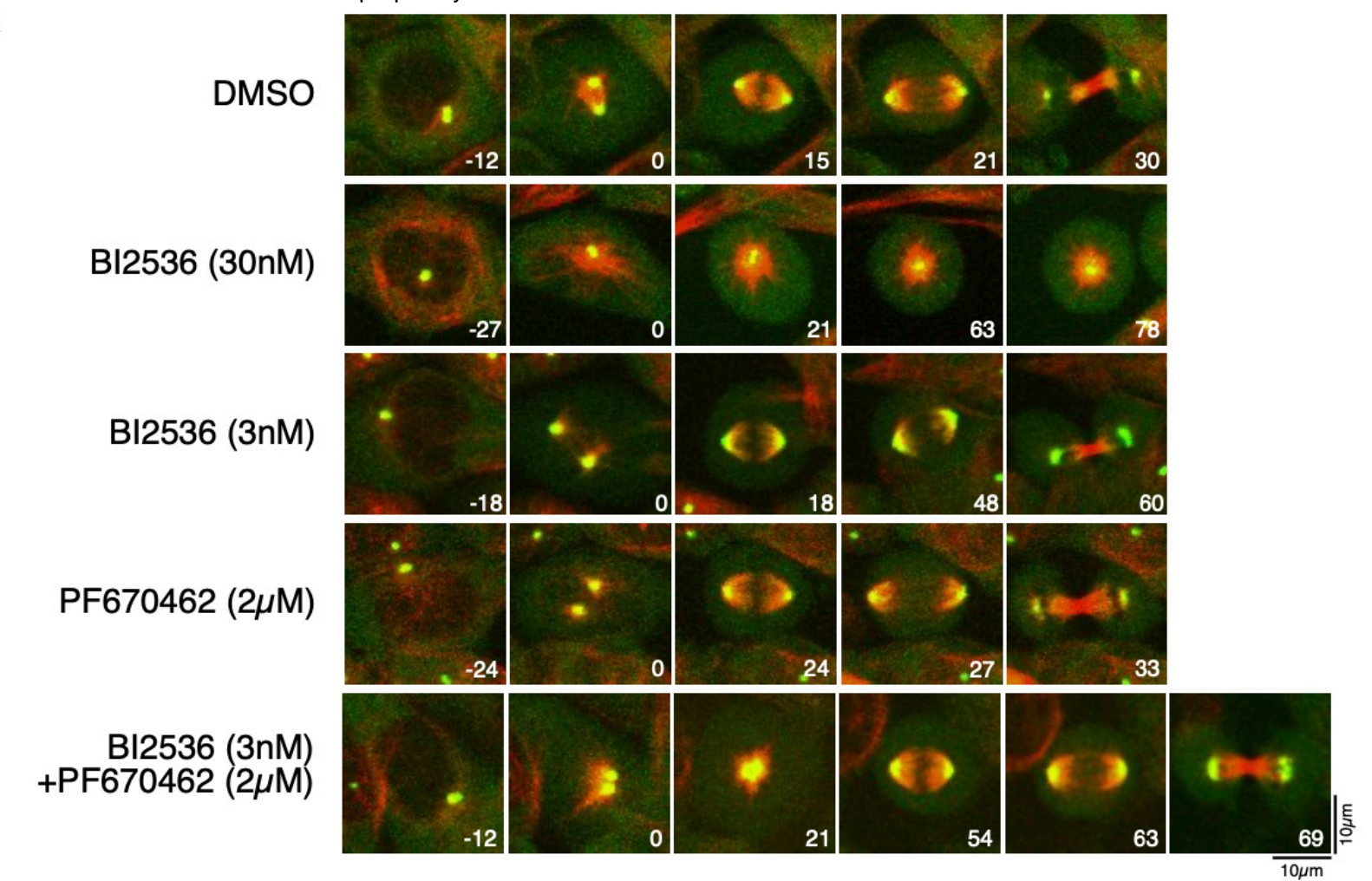

B

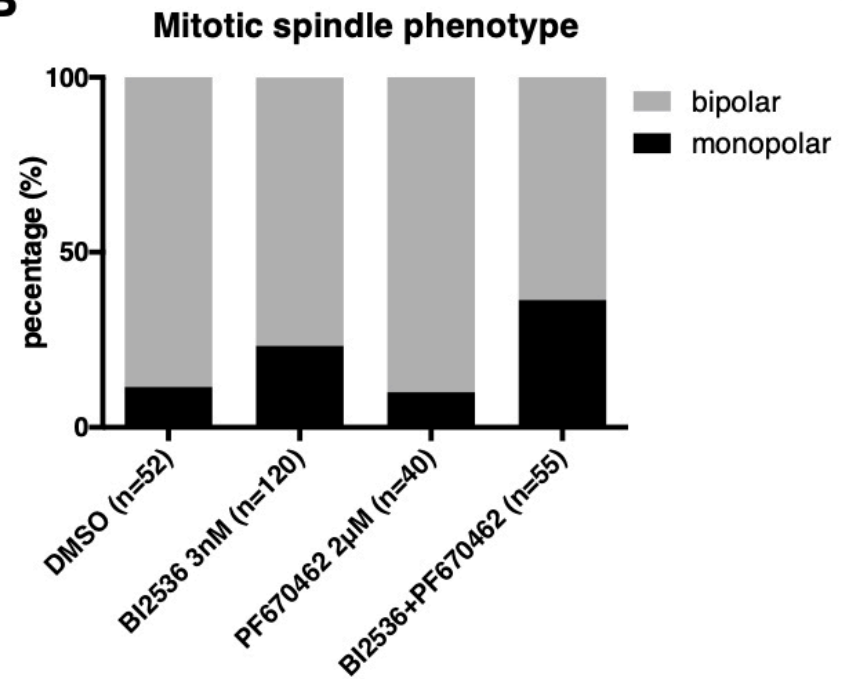

\section{Time from NEBD to bipolar spindle formation}

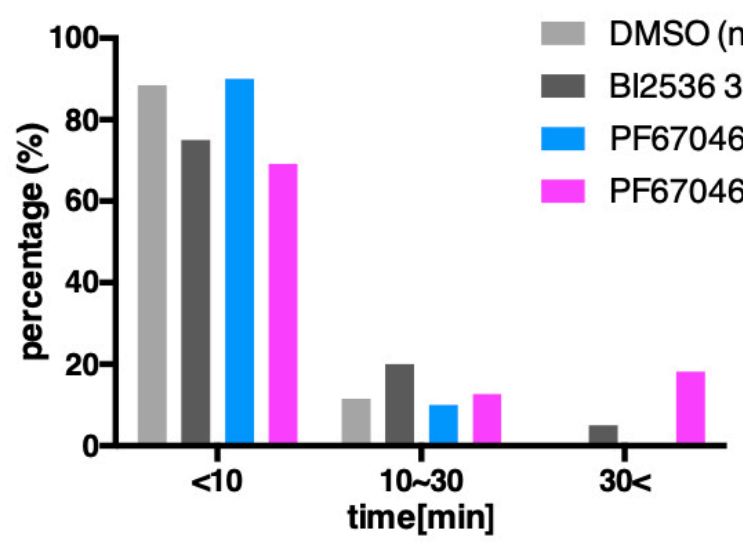

Figure 6. Synthetic monopolar spindle phenotype by partial inhibition of Polo-like kinase (Plk)1 and casein kinase I (CK1) $\delta$ in human colon cancer cells

(A) Mitosis of the HCT116 cell line in the presence of Plk1 and/or CK1 inhibitors (BI2536 for Plk1, PF670462 for CK1). Green, $\gamma$-tubulinmClover (endogenously tagged); Red, Sir-tubulin. (B) Frequency of monopolar spindles (monopolar state for $\geq 10 \mathrm{~min}$ ). (C) Duration of nuclear envelope breakdown (NEBD)-to-bipolar spindle formation. Time $0(\mathrm{~min})$ is set at the onset of spindle formation. 


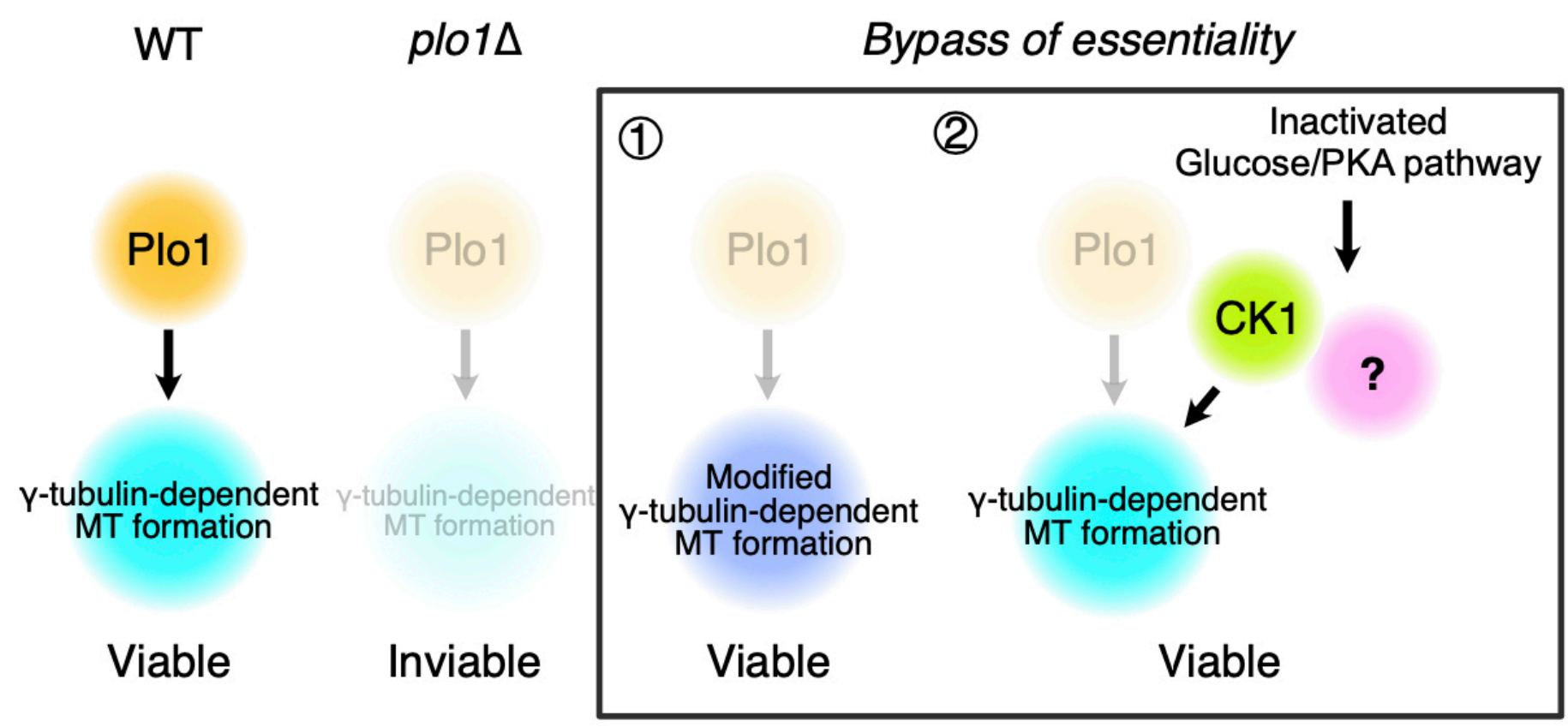

Figure 7: How Plo1 essentiality is bypassed

An increase in spindle microtubules (MTs) is the key to bypassing Plo1. This can be achieved by mutations in MT-associated proteins or nucleators (1) or global change in glucose metabolism (2), which involves casein kinase I and other unknown factors. 
bioRxiv preprint doi: https://doi.org/10.1101/2021.12.15.472863; this version posted December 16, 2021. The copyright holder for this preprint (which was not certified by peer review) is the author/funder, who has granted bioRxiv a license to display the preprint in

A
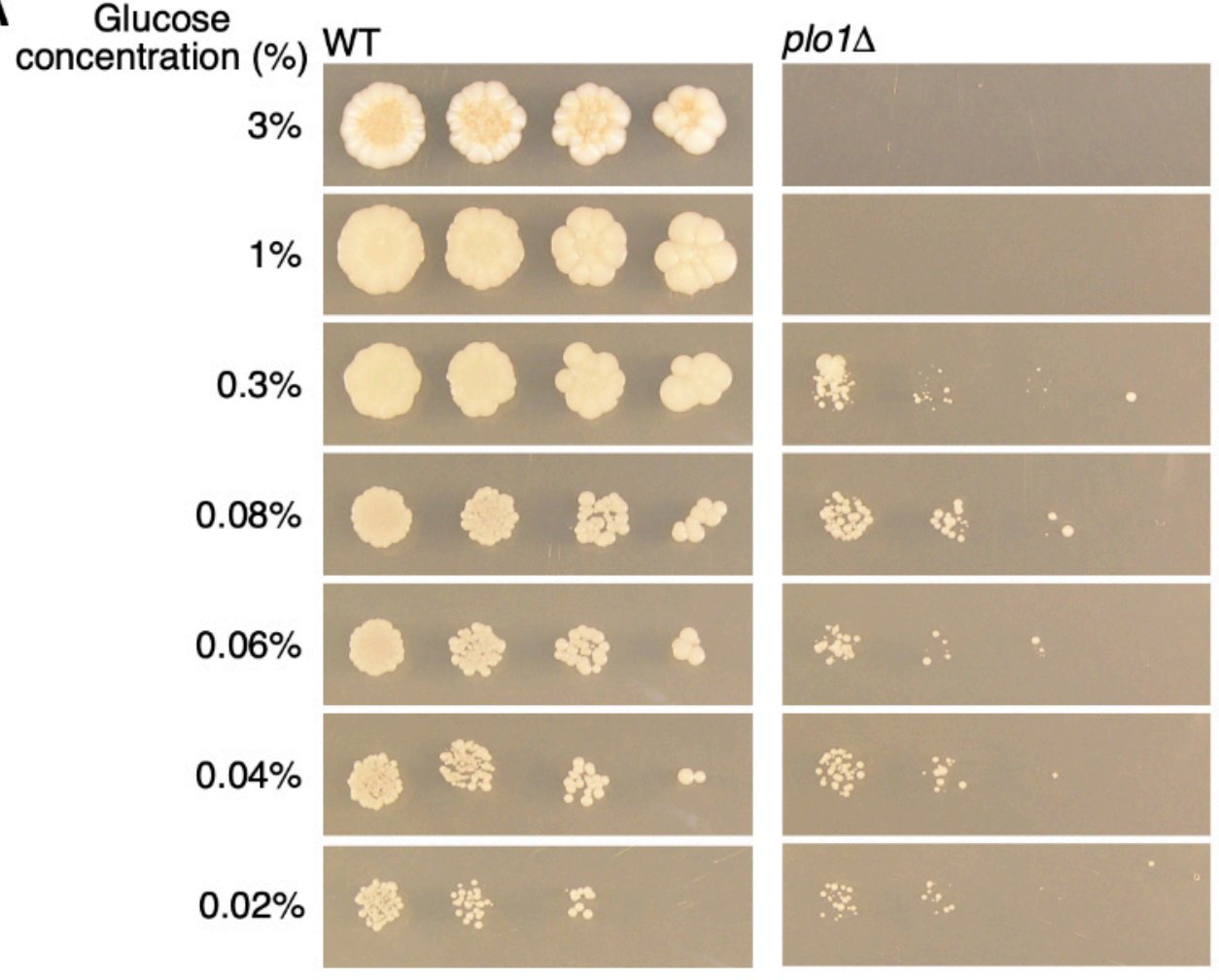

B

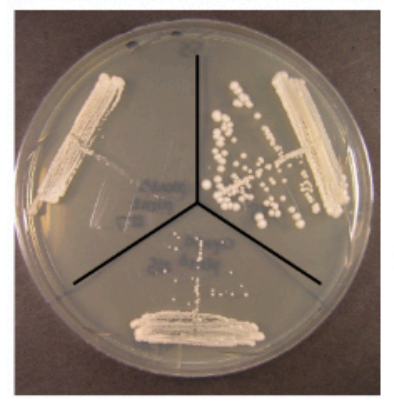

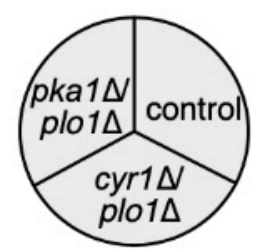

C

Ngg1E4_Q5delinsD* plo1 $:: G 418$ X rec6 $\Delta:: \mathrm{Hyg}$
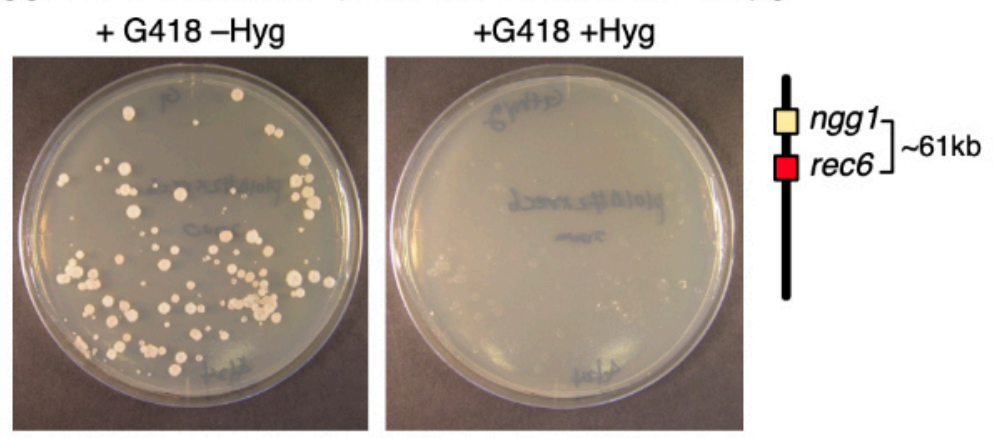

D

1st EVO plo1 add back

$32^{\circ} \mathrm{C}$

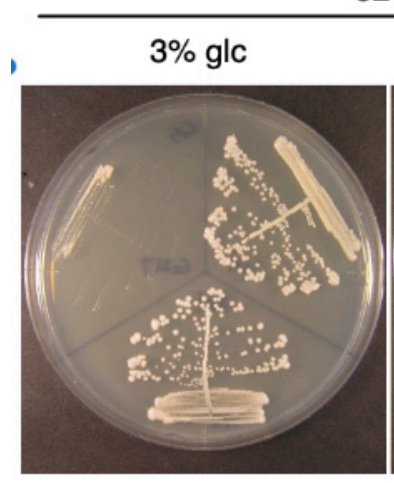

$0.08 \%$ glc

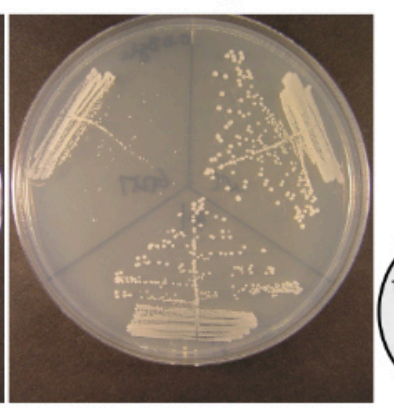

2nd EVO plo1 add back

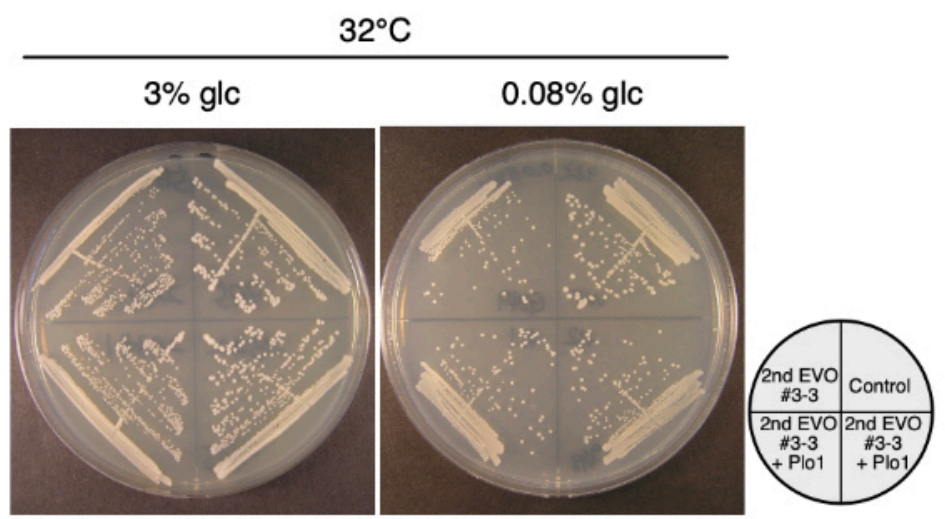

Figure S1. The bypass of essentiality (BOE) of Plo1

(A) Colony spotting on YE5S (+ G418, CHX) plates with various glucose concentrations. Spores $(7,500,1,500,300$, or 60$)$ were spotted and incubated for $5 \mathrm{~d}$ at $32^{\circ} \mathrm{C}$ (expected drug-resistant cell numbers: 1,875, 375, 75, and 15, respectively). (B) Disruptant of PKA (pkal) or adenylate cyclase $(\mathrm{cyrl})$ bypassed Plo1 essentiality. Colonies were grown on YE5S plates for $4 \mathrm{~d}$ at $32^{\circ} \mathrm{C}$. (C) An example of suppressor mutation confirmation based on linkage test. $n g g l$ and rec6 genes are closely located on chromosome II. Double plol $\Delta$ rec6 $\Delta$ was never obtained after crossing rec6 $\Delta$ (marked with hygromycin resistance) with a surviving plo1 $\Delta$ strain (G418 resistant) in which a mutation was identified in ngg1. (D) Experimental evolution (EVO) of plo1 $1 \Delta$ strain was performed sequentially, as described in Fig. 1A. After each round, we isolated a few of the fastest growing colonies. We converted plo1 $\Delta$ to plo1+ and tested if this enhanced the colony growth. Return of Plo1 helped colony growth of a strain obtained after the $1^{\text {st }}$ round of evolution (left, strain \#3), whereas a further evolved strain was insensitive to Plo1 (right, strain \#3-3). Two glucose concentrations were tested (3\% and $0.08 \%$ ). Wild-type was used as the control. 
bioRxiv preprint doi: https://doi.org/10.1101/2021.12.15.472863; this version posted December 16, 2021. The copyright holder for this

preprint (which was not certified by peer review) is the author/funder, who has granted bioRxiv a license to display the preprint in

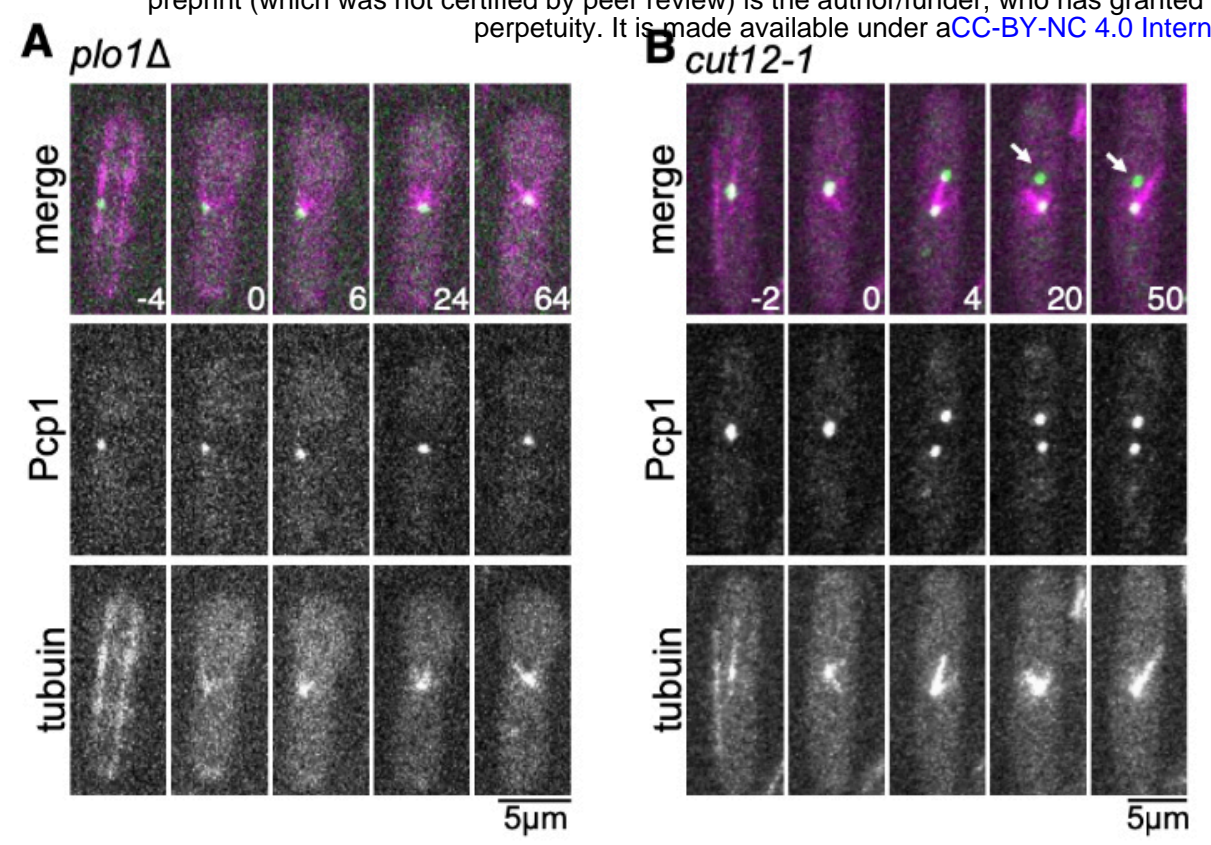

\section{C plo1s}
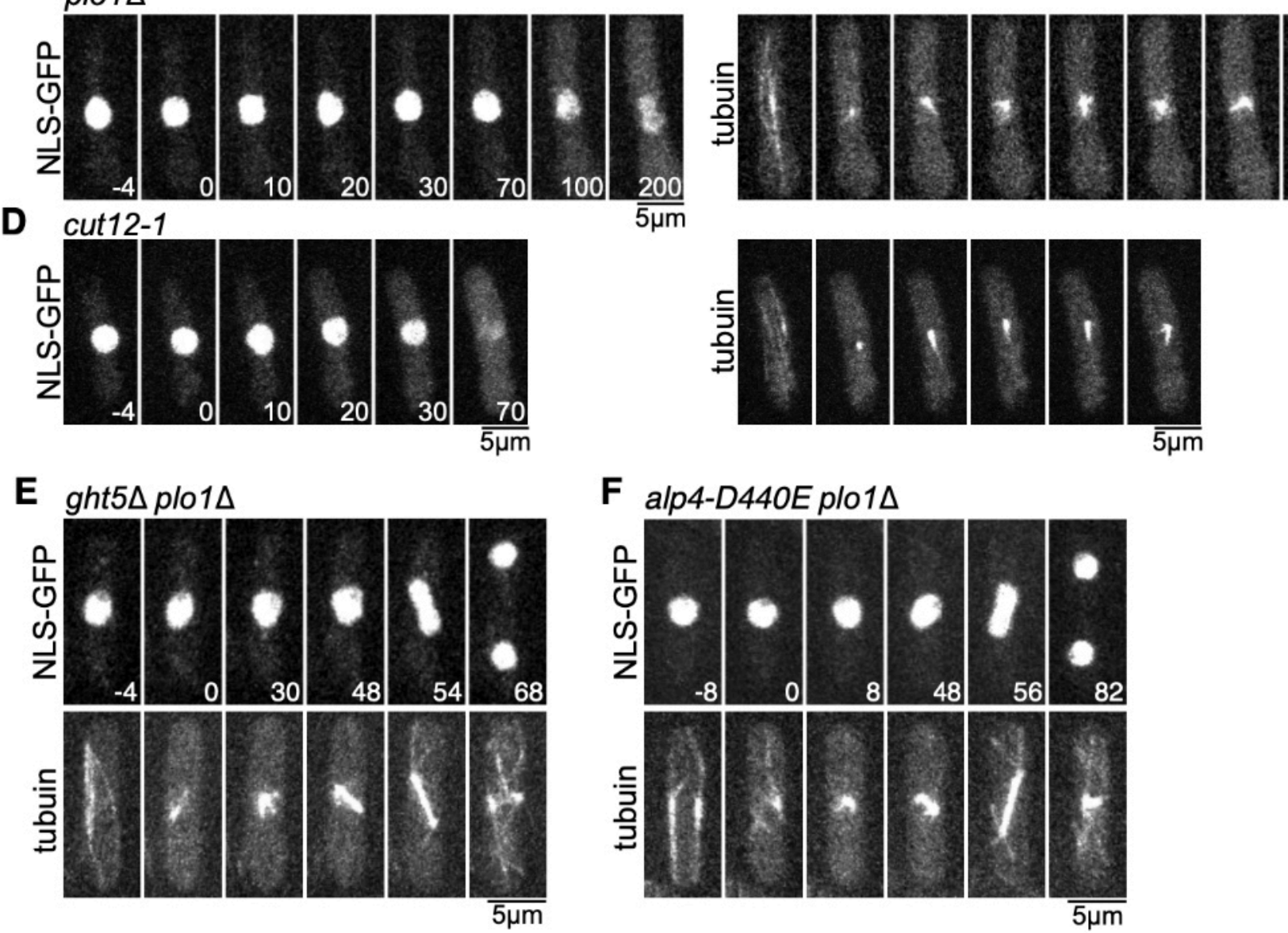

F alp4-D440E plo1

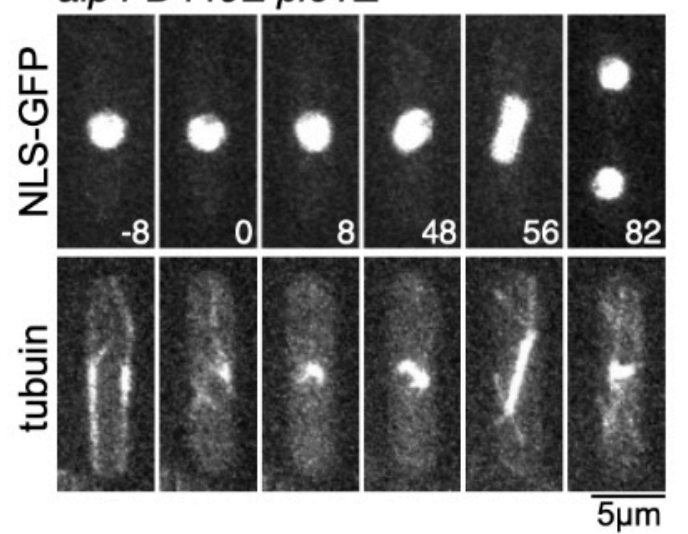

Figure S2. Nuclear envelope appears to be intact in plo1 $\Delta$

(A, B) Live imaging of plo $1 \Delta$ and cut $12-1$ strains expressing Pcp $1^{\text {pericentrin }}$-GFP and mCherry-tubulin. cut $12-1$ cells were incubated at $36^{\circ} \mathrm{C}$ for $3 \mathrm{~h}$ before imaging. (C-F) Live imaging of plo1 $\Delta$, cut12-1, ght5 $\Delta$ plol $\Delta$, and alp4-D440E plo1 $\Delta$ strains expressing NLS-GFP- $\beta$-Gal and mCherry-tubulin. cut $12-1$ cells were incubated at $36^{\circ} \mathrm{C}$ for $3 \mathrm{~h}$ before imaging. Time $0(\mathrm{~min})$ was set at the onset of spindle formation. 
bioRxiv preprint doi: https://doi.org/10.1101/2021.12.15.472863; this version posted December 16, 2021. The copyright holder for this preprint (which was not certified by peer review) is the author/funder, who has granted bioRxiv a license to display the preprint in

A perpetuity. It is made available under aCC-BY-NC 4.0 International license.

$\mathrm{TBZ}(\mu \mathrm{g} / \mathrm{ml})$

0

0.1

2

5
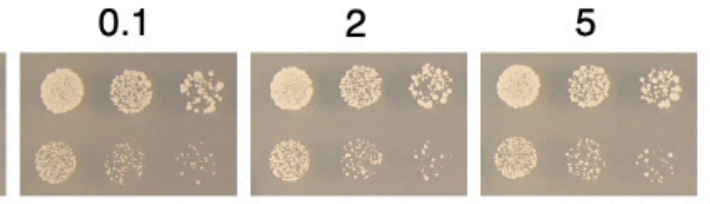

10

20

Control

plo1s
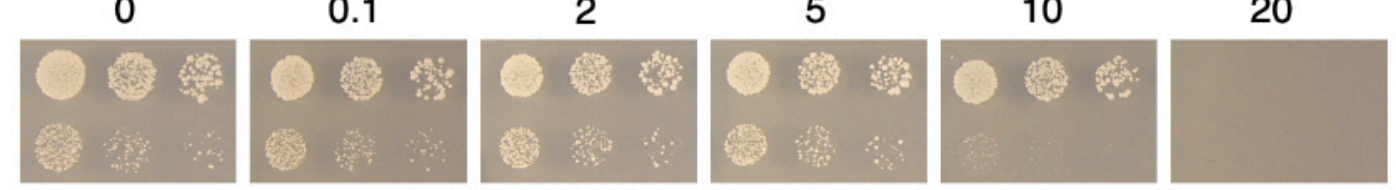

$0.08 \%$ Glc YE5S

\section{B WT}

merge
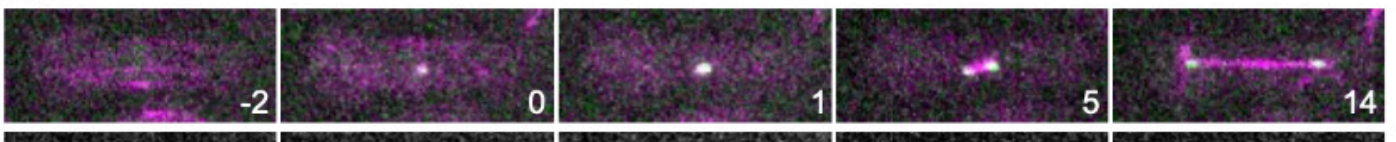

Cut7
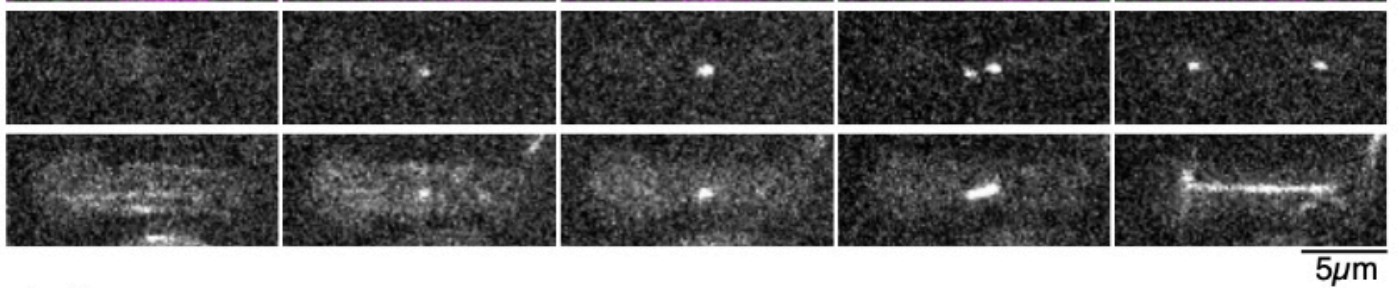

\section{plo1s}
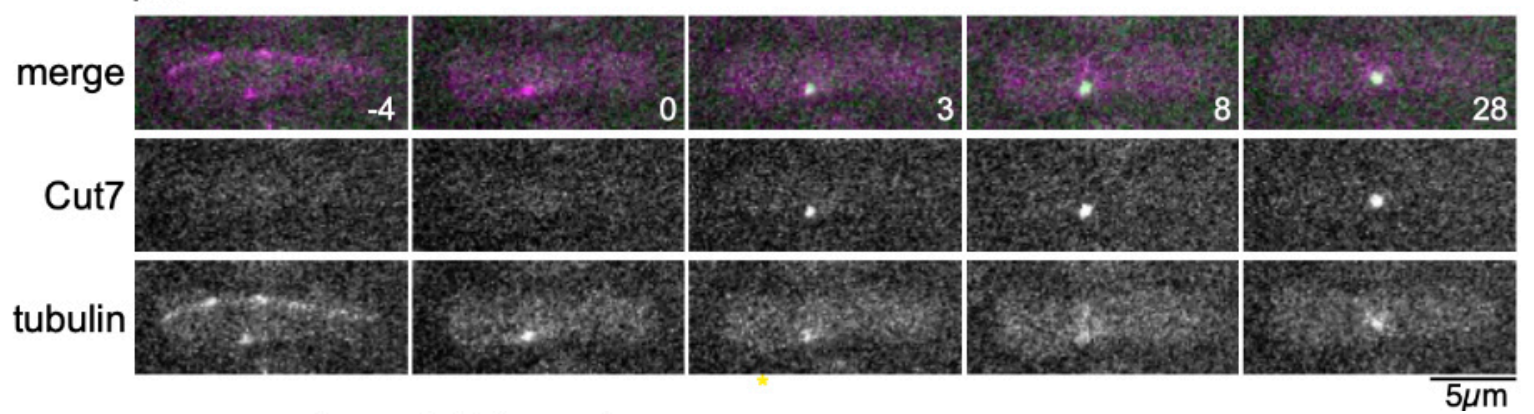

C

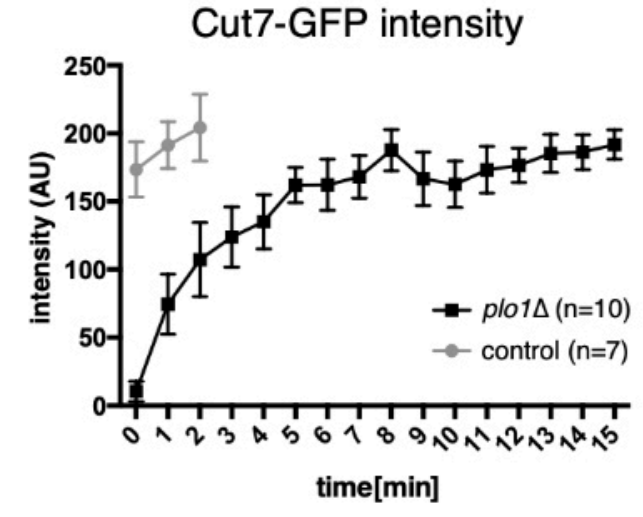

D
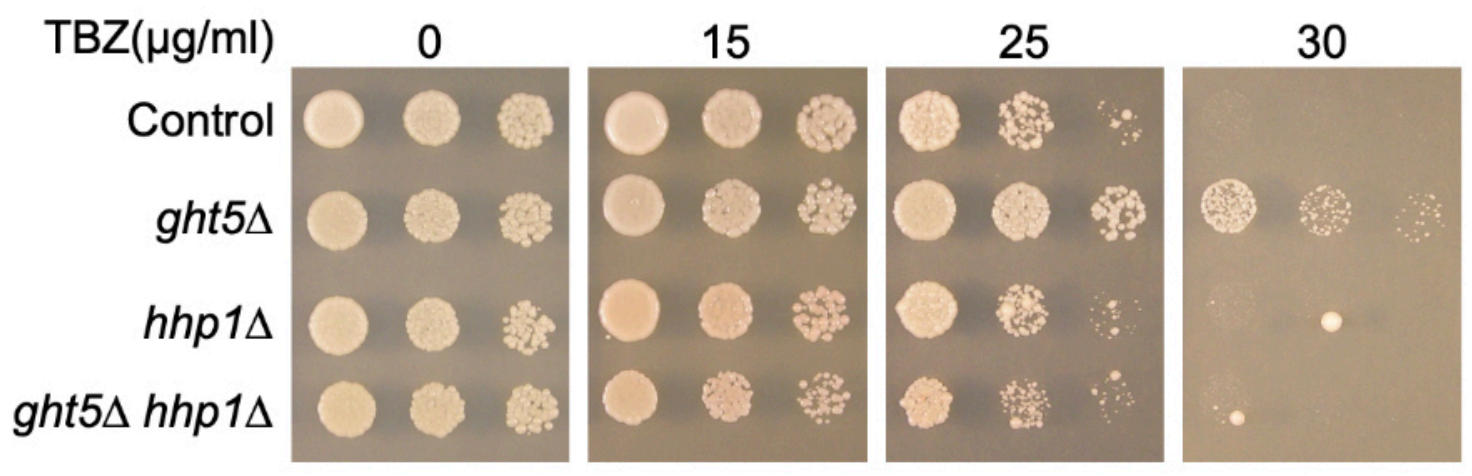

Figure S3. plo1 deletion is sensitive to thiabendazole (TBZ) but does not critically affect Cut $7^{\text {kinesin-5 }}$ localisation

(A) In the presence of $10 \mu \mathrm{g} / \mathrm{mL}$ TBZ, plo $1 \Delta$ failed to form colonies even in low glucose medium. Spores $(10,000,2,000$, and 400$)$ were spotted and colonies were formed on $0.08 \%$ glucose, G418-containing plates for $5 \mathrm{~d}$ at $32^{\circ} \mathrm{C}$ (expected G418-resistant cell numbers: 5,000 , 1,000 , and 200 cells, respectively). (B, C) Failure in spindle bipolarisation even when Cut $7^{\text {kinesin-5}-G F P ~ a c c u m u l a t e d ~ o n ~ t h e ~ S P B ~ a t ~ a ~}$ normal level after a delay in plo1s. (D) ght $5 \Delta$ confers resistance to TBZ, whereas $h h p 1 \Delta$ suppresses the effect. Cells $(5,000,1,000$, and 200 cells $)$ spotted and cultured in YE5S medium for $3 \mathrm{~d}(0$ and $15 \mu \mathrm{g} / \mathrm{mL}$ TBZ plates $)$ or $6 \mathrm{~d}\left(25 \mathrm{and} 30 \mu \mathrm{g} / \mathrm{mL} \mathrm{TBZ} \mathrm{plates)} \mathrm{at} 32^{\circ} \mathrm{C}\right.$. Time $0(\mathrm{~min})$ is set at the onset of spindle formation. 
bioRxiv preprint doi: https://doi.org/10.1101/2021.12.15.472863; this version posted December 16, 2021. The copyright holder for this

preprint (which was not certified by peer review) is the author/funder, who has granted bioRxiv a license to display the preprint in

A $3 \%$ glucose YE5S

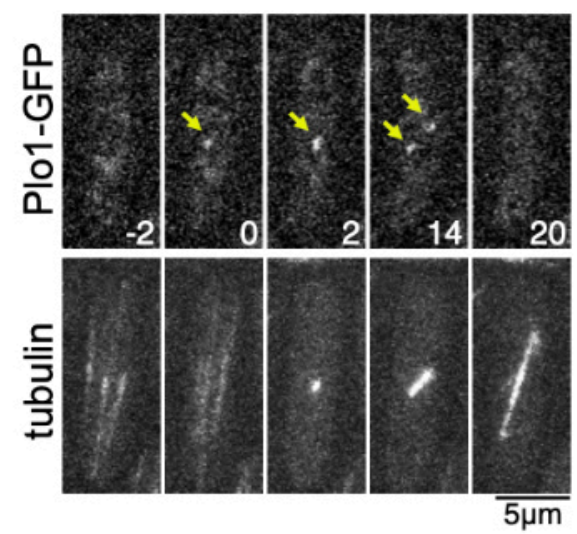

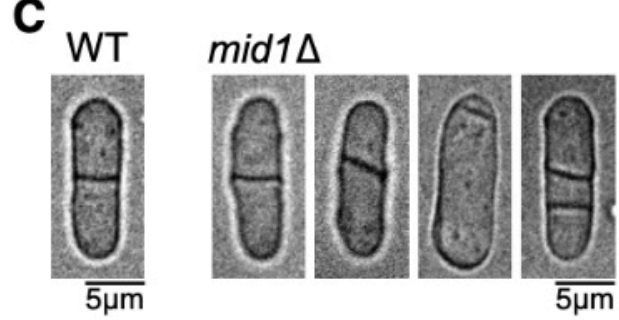

B $\quad 0.08 \%$ glucose YE5S
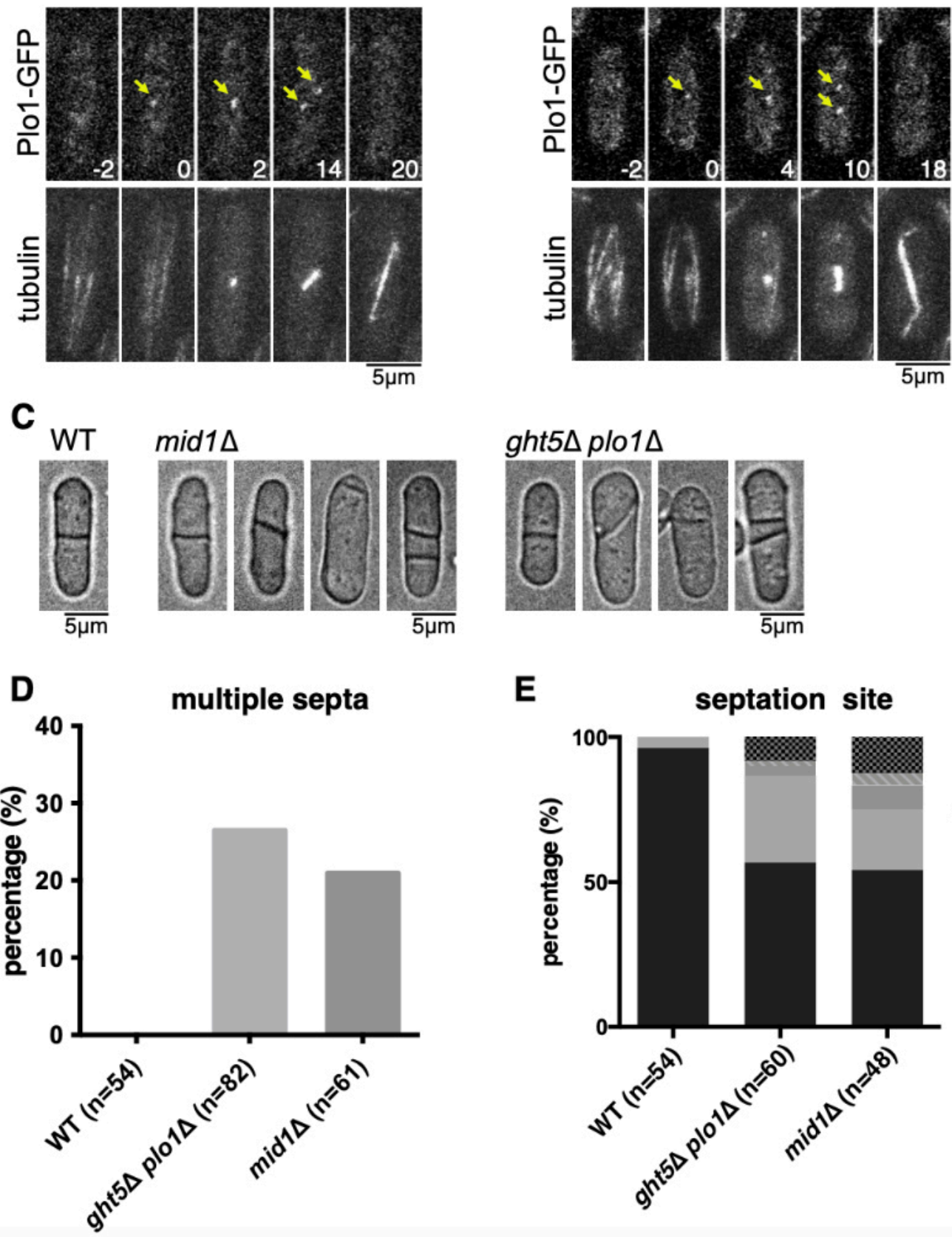

E

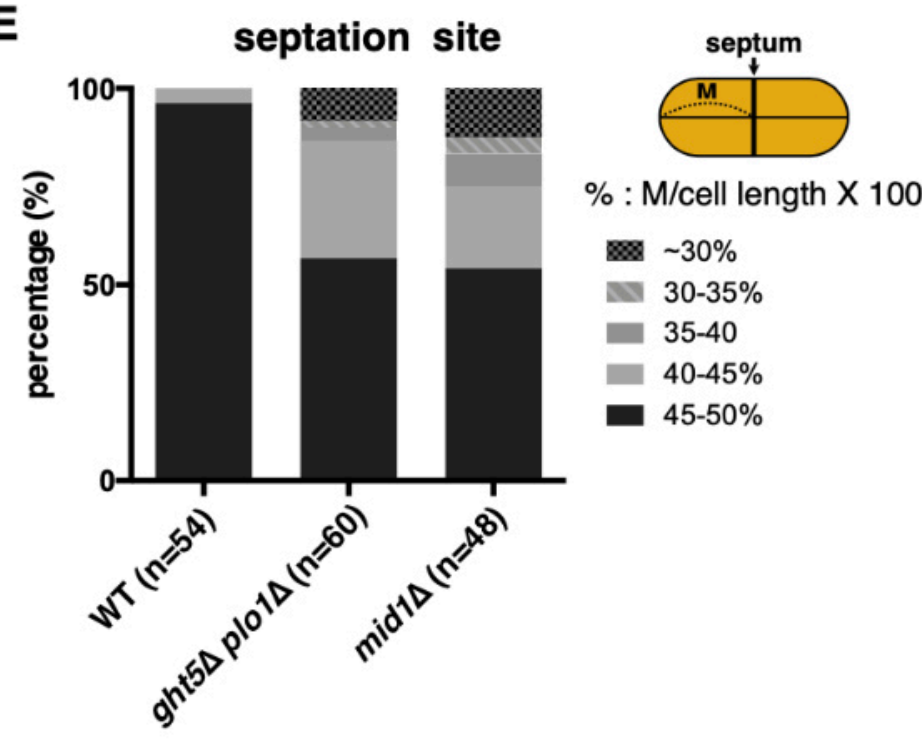

Figure S4. Septation defect of plo1 $\Delta$ is not rescued by ght 5 deletion

(A, B) Live imaging of plo1 $\Delta$ strains expressing Plo1-GFP and mCherry-tubulin. Cells were incubated in the YE5S medium containing $3 \%$ or $0.08 \%$ glucose. Arrows indicate Plol-GFP signals at SPBs. Time 0 (min) was set at the onset of spindle formation. (C) Bright field images of wild-type (WT), mid1 $\Delta$, and ght $5 \Delta$ plo $1 \Delta$. (D) Quantification of multiseptated cells. A total of $21 \%$ of mid1 $\Delta$ cells and $26 \%$ of ght $5 \Delta$ plo1 $\Delta$ cells had multiple septations, whereas this was never observed in control cells. (E) Quantification of the septation site. Relative position of the septum along the long axis of the cell was determined. 
bioRxiv preprint doi: https://doi.org/10.1101/2021.12.15.472863; this version posted December 16, 2021. The copyright holder for this preprint (which was not certified by peer review) is the author/funder, who has granted bioRxiv a license to display the preprint in

A perpetuity. It is made available under aCC-BY-NC 4.0 International license.

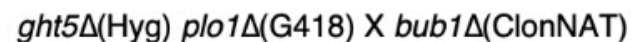

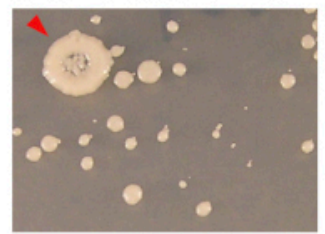

$+\mathrm{G} 418$

+ Hygromycin

- ClonNAT

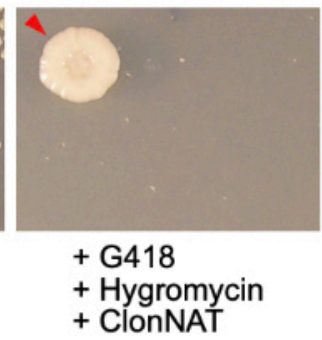

B

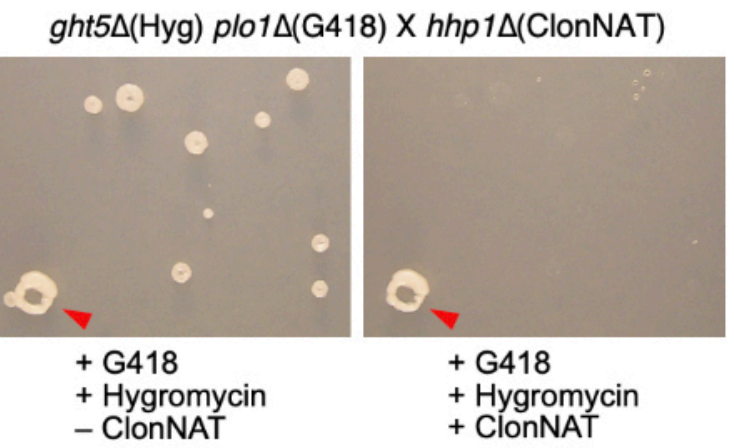

C

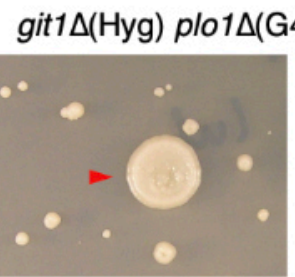

$+\mathrm{G} 418$

+ Hygromycin

- BSD
D

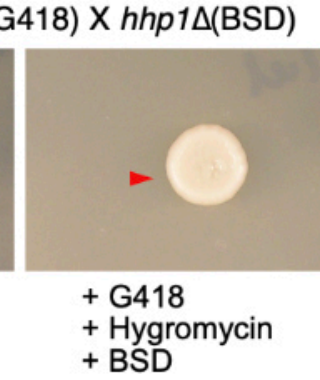

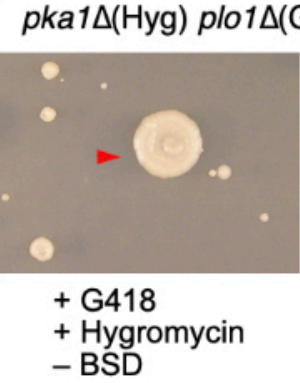

E

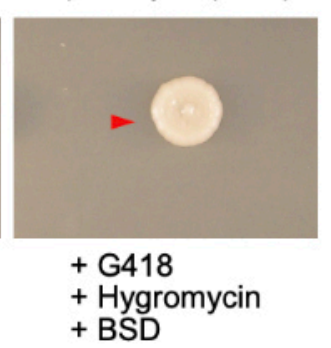

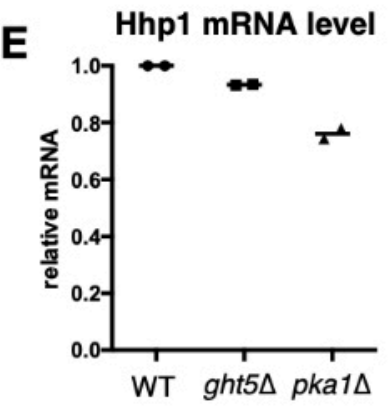

F
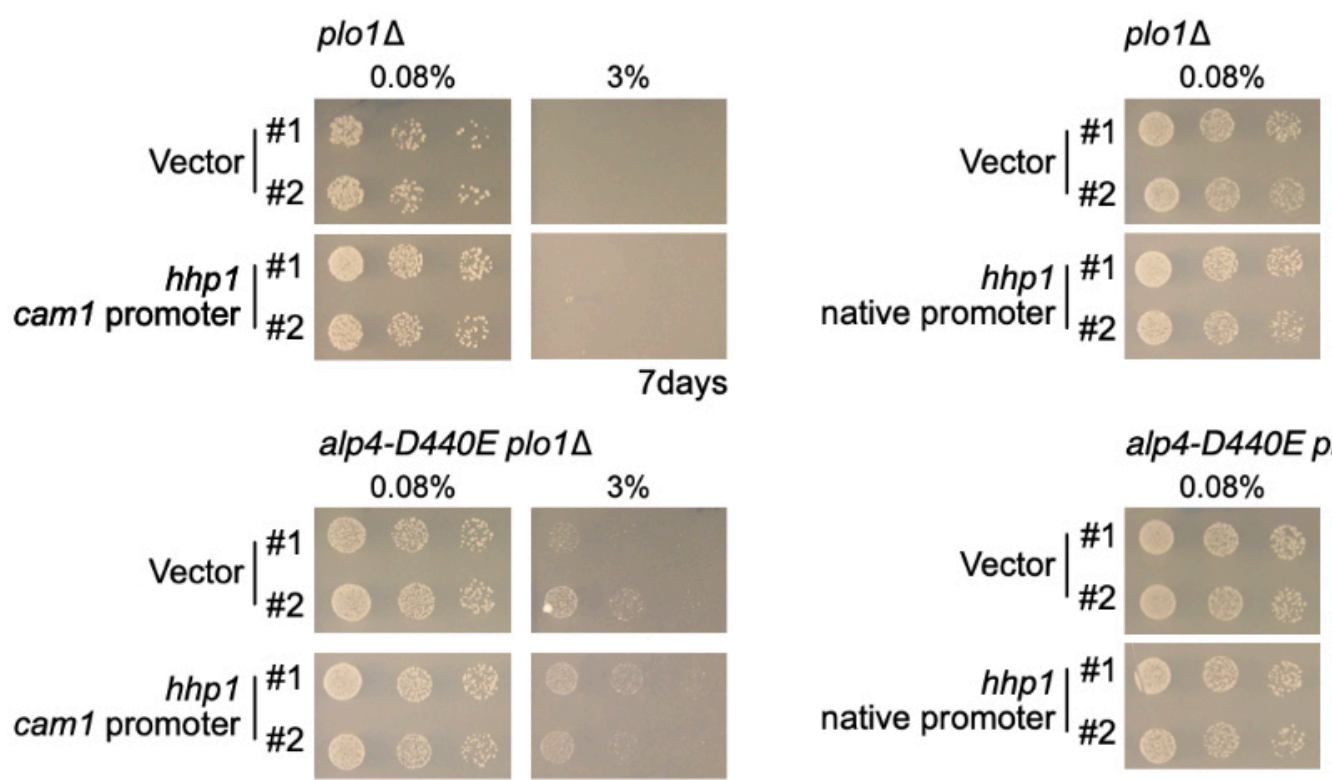

7days $3 \%$

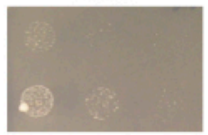

5days
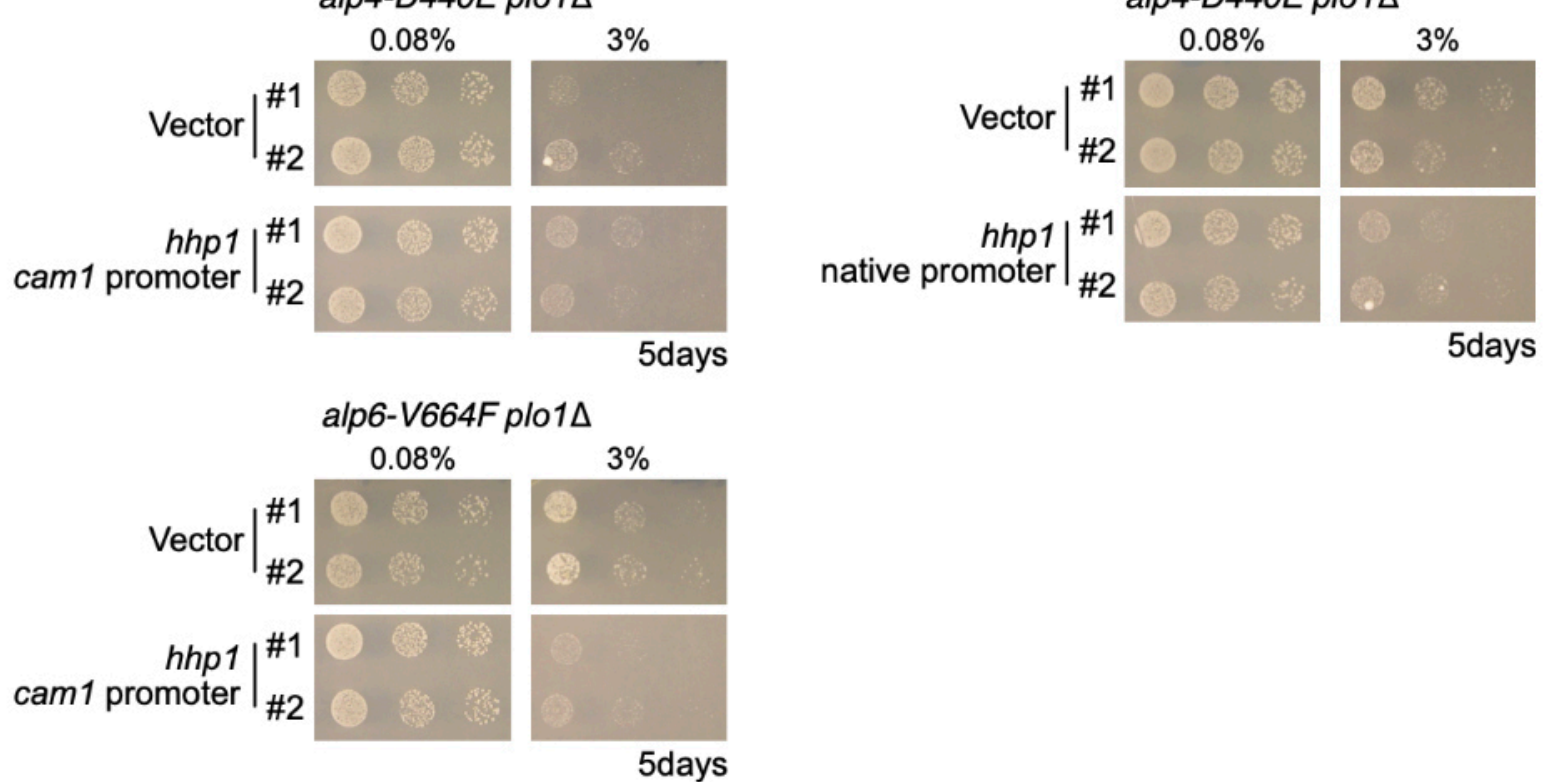

Figure S5. ght5 $\mathrm{plo1}$ is synthetic lethal with $h h p 1 \Delta$, but Hhp1 ${ }^{\mathrm{CK} 1}$ overexpression alone does not increase the colony growth of plo1 1 .

(A-D) Confirmation of synthetic lethality between the indicated strains by random spore spreading followed by replica-plating onto drugcontaining plates. The $b u b l$ and $h$ hpl ORFs were replaced with ClonNAT-resistant or BSD-resistant cassettes. The plol ORF was replaced with a G418-resistant cassette. ght 5, git1, and pkal were replaced with a hygromycin-resistant cassette. Colony formation of heterozygous

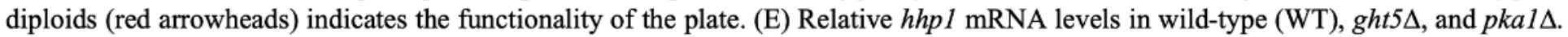
Data from two independent experiments were plotted. (F) Investigation of the rescue ability by Hhpl overexpression in the indicated strains. The calmodulin promoter (cam1-pr) (67) and the native promoter of $h h p 1^{+}$gene were used. Hhpl was expressed in the $p l o 1 \Delta$, alp4-D440E plo1 1 , and alp6-V664F plo1 $\Delta$ strains. Cells $(10,000,5,000$, and 1,000) were spotted and cultured in YE5S with G418 for 5 d at $32^{\circ} \mathrm{C}$. 